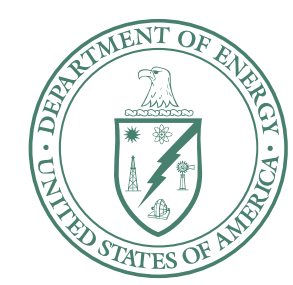

U.S. Department of Energy

Idaho Operations Office

\title{
Field Sampling Plan for the Operable Units 6-05 and 10-04 Remedial Action, Phase IV
}

November 2006 
DOE/ID-11280

Revision 0

Project No. 23368

\section{Field Sampling Plan for the Operable Units 6-05 and 10-04 Remedial Action, Phase IV}

November 2006

Prepared for the U.S. Department of Energy DOE Idaho Operations Office 



\begin{abstract}
This Field Sampling Plan outlines the collection and analysis of samples in support of Phase IV of the Waste Area Group 10, Operable Units 6-05 and 10-04 remedial action. Phase IV addresses the remedial actions to areas with the potential for unexploded ordnance at the Idaho National Laboratory Site. These areas include portions of the Naval Proving Ground, the Arco High-Altitude Bombing Range, and the Twin Buttes Bombing Range. Five areas within the Naval Proving Ground that are known to contain unexploded ordnance include the Naval Ordnance Disposal Area, the Mass Detonation Area, the Experimental Field Station, the Rail Car Explosion Area, and the Land Mine Fuze Burn Area. The remedial action will be concentrated in these five areas. The remedial action consists of removal and disposal of ordnance by high-order detonation, followed by sampling to determine the extent, if any, of soil that might have been contaminated by the detonation activities associated with the disposal of ordnance during the Phase IV activities and explosives during the Phase II activities.
\end{abstract}




\section{CONTENTS}

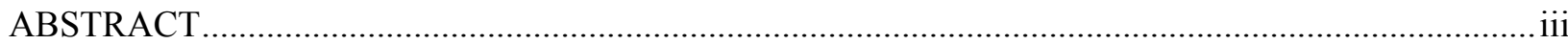

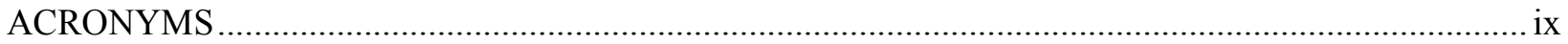

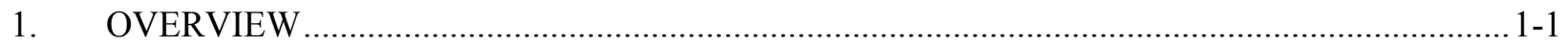

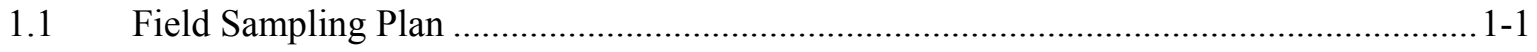

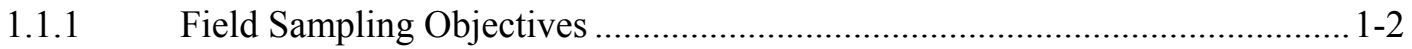

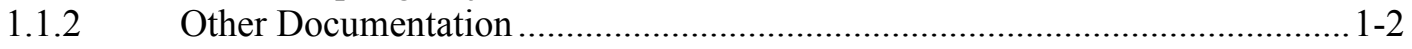

1.2 Project Organization and Responsibility ............................................................. 1-2

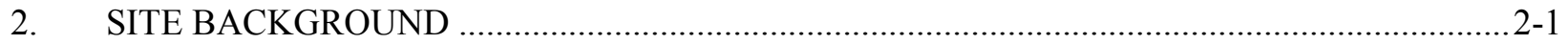

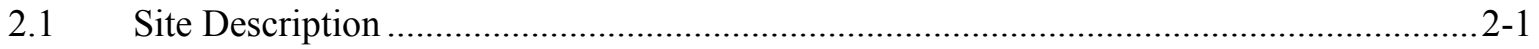

2.1.1 Naval Ordnance Disposal Area ............................................................. 2-1

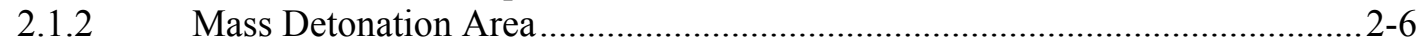

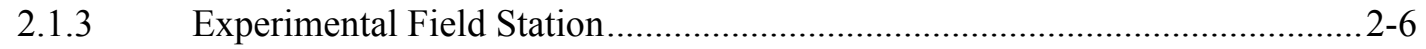

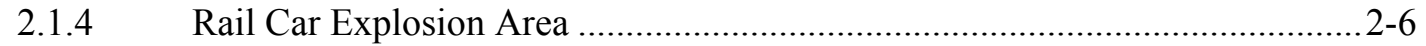

2.1.5 Land Mine Fuze Burn Area....................................................................2-6

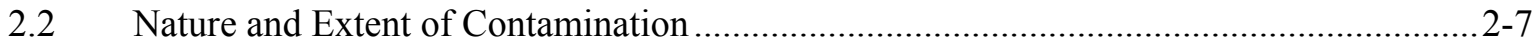

2.2.1 Naval Ordnance Disposal Area ..................................................................... $2-7$

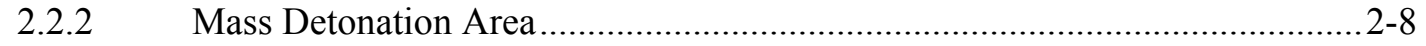

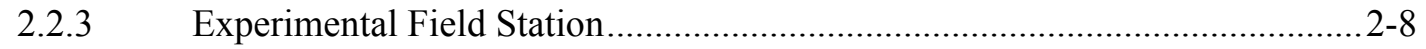

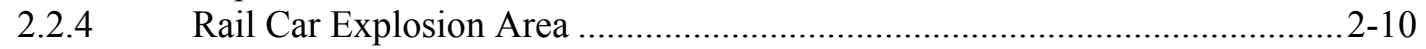

2.2.5 Land Mine Fuze Burn Area................................................................. 2-10

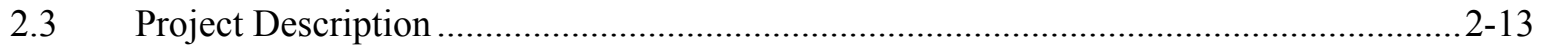

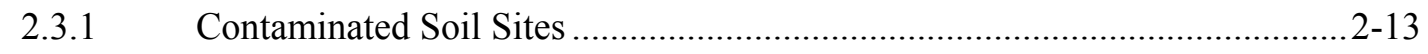

3. SAMPLING DATA QUALITY OBJECTIVES .................................................................

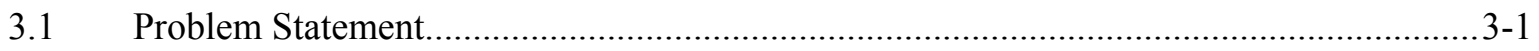

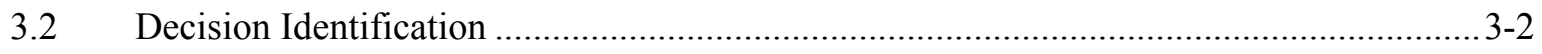

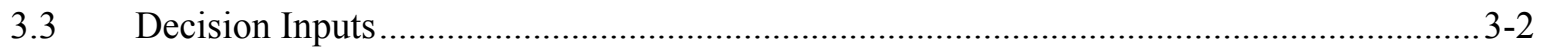

3.3.1 Information Required to Resolve Decision Statements ................................ 3-2

3.3.2 Basis for Setting the Action Level .............................................................. 3-3

3.3.3 Computational and Survey/Analytical Methods .......................................... 3-3

3.3.4 Analytical Performance Requirements........................................................ 3-4 


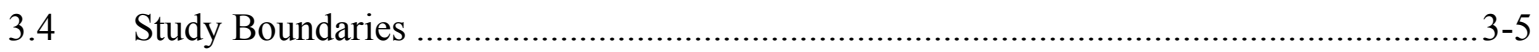

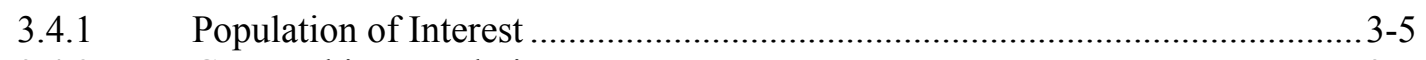

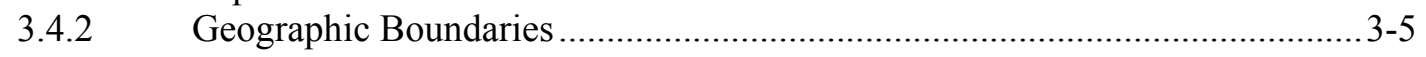

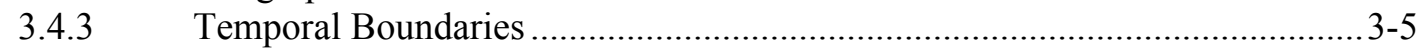

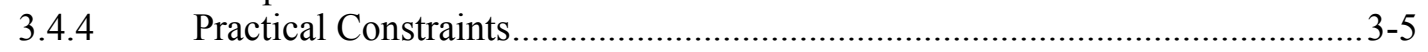

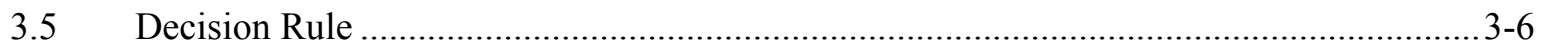

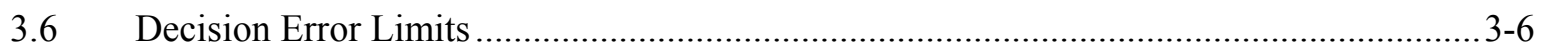

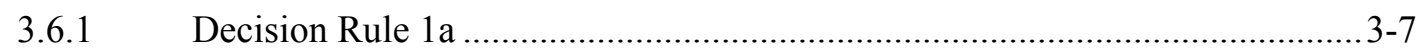

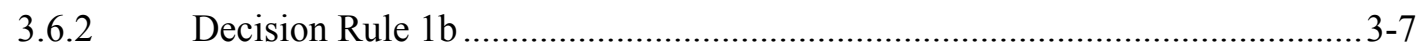

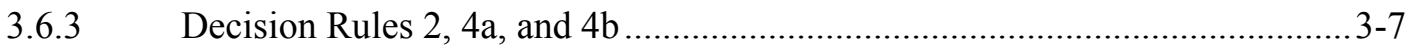

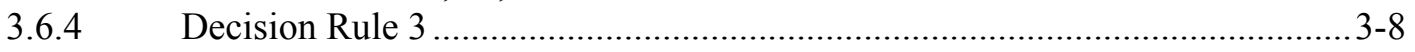

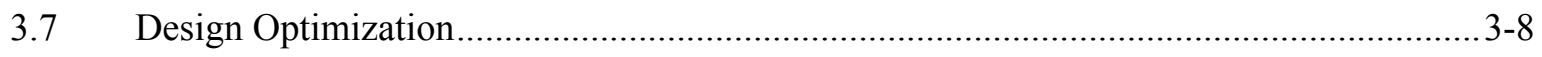

3.7.1 Soil Contamination Characterization ...................................................... 3-8

3.7.2 Soil Removal Survey...........................................................................

3.7.3 Sampling for Characteristic Determination............................................... 3-9

3.7.4 Statistical Sampling Design for Soil ...................................................... 3-10

3.8 Quality Assurance Objectives for Measurement ....................................................... 3-12

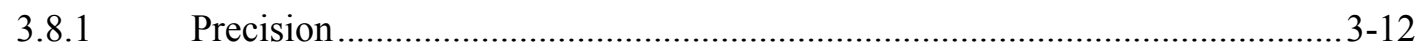

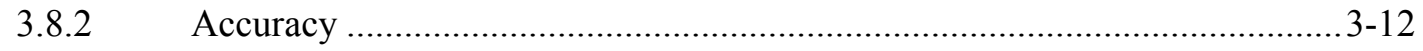

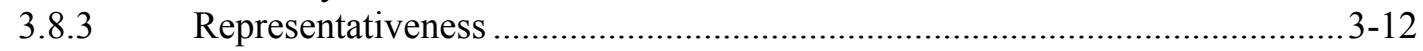

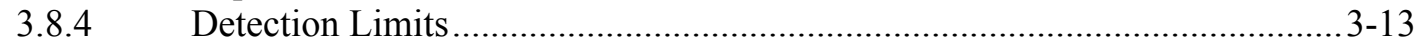

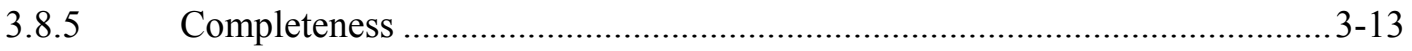

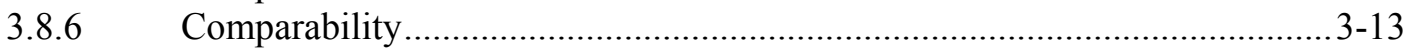

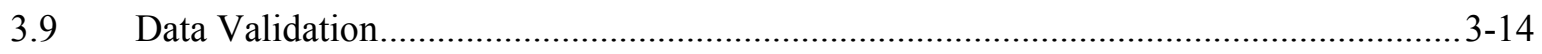

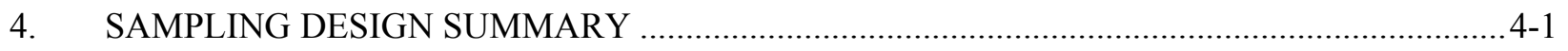

4.1 Quality Assurance/Quality Control Samples.............................................................. 4-1

4.2 Sampling Locations and Frequency ............................................................... $4-1$

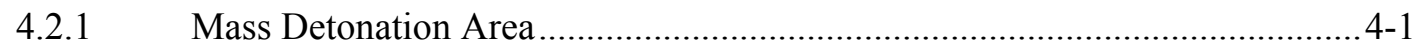

Impacted Soil Areas ............................................................................

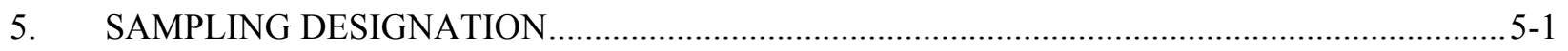

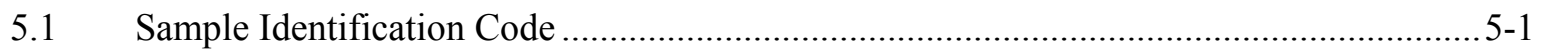

5.2 Sampling and Analysis Plan Table/Database ......................................................... 5-1

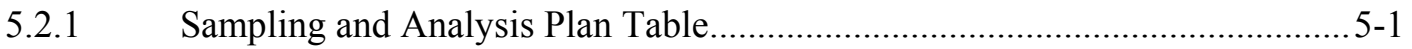

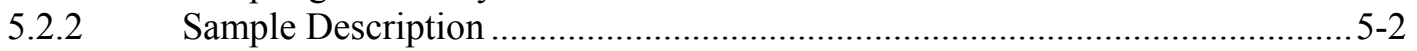




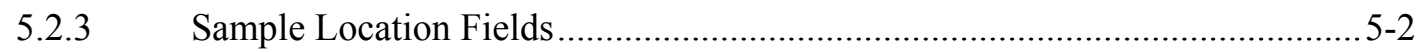

5.2.4 Analysis Types (AT1-AT2O) .............................................................. 5-3

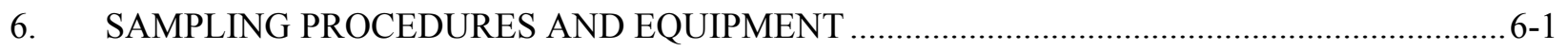

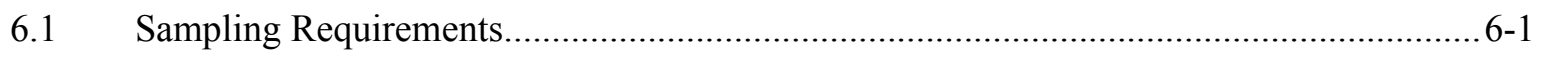

6.1.1 Field Measurements ............................................................................. 6-1

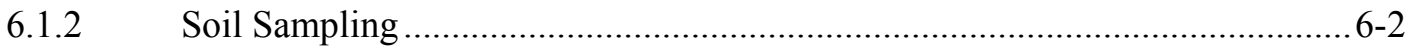

6.2 Handling and Disposition of Sampling Residues and Related Waste .............................. 6-3

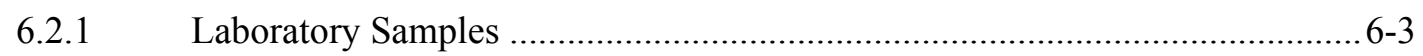

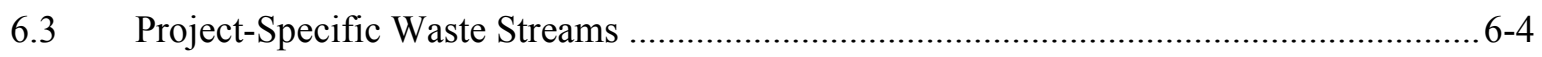

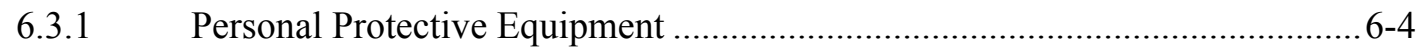

6.3.2 Unused/Unaltered Sample Material .......................................................6-4

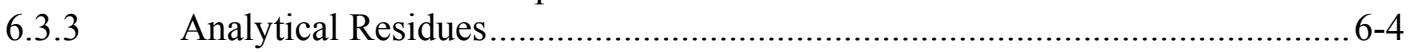

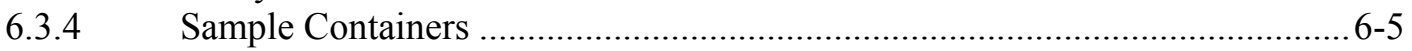

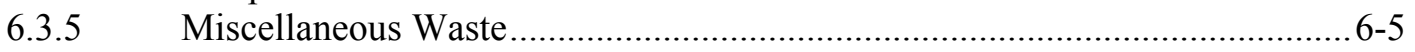

6.3.6 Contaminated Sampling Equipment...................................................... 6-5

7. DOCUMENTATION MANAGEMENT AND SAMPLE CONTROL ...................................... $7-1$

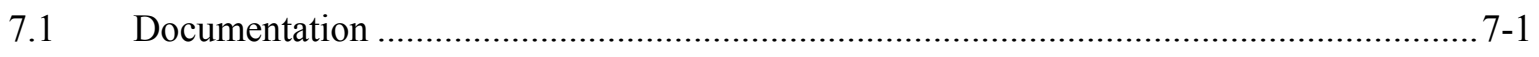

7.1.1 Sample Container Labels ................................................................... $7-1$

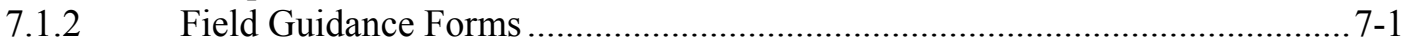

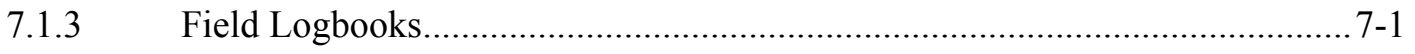

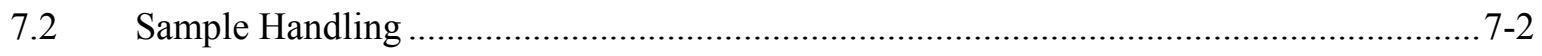

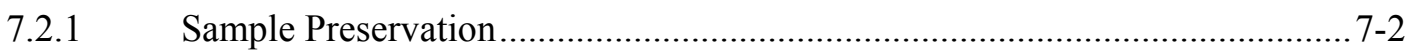

7.2.2 Chain-of-Custody Procedures ..............................................................

7.2.3 Transportation of Samples ......................................................................

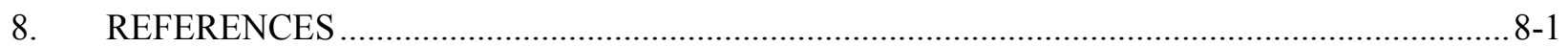




\section{FIGURES}

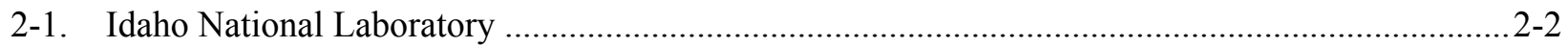

2-2. Location of Waste Area Group 10 Comprehensive Environmental Response, Compensation, and Liability Act sites at the Idaho National Laboratory .....................................2-3

2-3. Location of the unexploded ordnance-contaminated sites........................................................2-4

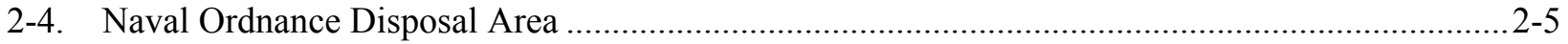

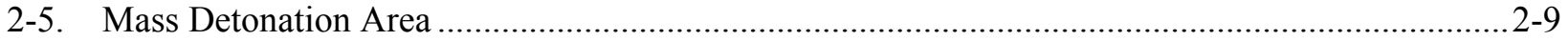

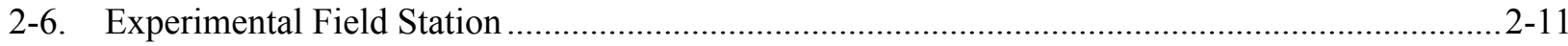

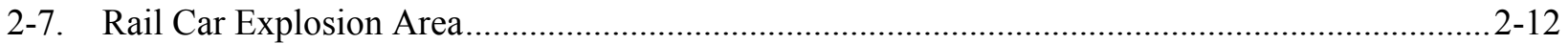

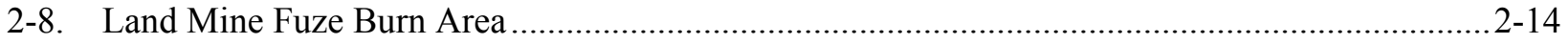

\section{TABLES}

3-1. Information required to resolve the decision statements ...........................................................

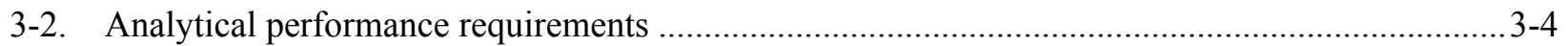

3-3. Decision rules for the Operable Unit 10-04 Phase IV areas ..................................................... 3-6

6-1. Specific sample requirements for the Operable Unit 10-04 Phase IV remedial action ..................6-1 


\section{ACRONYMS}

ARAR applicable or relevant and appropriate requirement

AWM amber wide-mouth

CERCLA Comprehensive Environmental Response, Compensation, and Liability Act

CFA Central Facilities Area

CFR Code of Federal Regulations

COC contaminant of concern

DEQ (Idaho) Department of Environmental Quality

DNB dinitrobenzene

DNT dinitrotoluene

DOE Department of Energy

DOE-ID Department of Energy Idaho Operations Office

DOT Department of Transportation

DQO data quality objective

DS decision statement

EPA Environmental Protection Agency

FSP field sampling plan

GDE guide

HASP health and safety plan

ICDF Idaho CERCLA Disposal Facility

ICP Idaho Cleanup Project

ID identification

INL Idaho National Laboratory

INTEC Idaho Nuclear Technology and Engineering Center

MCP management control procedure

MDA Mass Detonation Area 


$\begin{array}{ll}\text { NODA } & \text { Naval Ordnance Disposal Area } \\ \text { NPG } & \text { Naval Proving Ground } \\ \text { NRF } & \text { Naval Reactors Facility } \\ \text { OU } & \text { operable unit } \\ \text { PLN } & \text { plan } \\ \text { PPE } & \text { personal protective equipment } \\ \text { ppm } & \text { parts per million } \\ \text { PQL } & \text { practical quantitation limit } \\ \text { PRD } & \text { program requirements document } \\ \text { PSQ } & \text { principal study question } \\ \text { QA } & \text { quality assurance } \\ \text { QAPjP } & \text { Quality Assurance Project Plan } \\ \text { QC } & \text { quality control } \\ \text { RCRA } & \text { Resource Conservation and Recovery Act } \\ \text { RD/RA } & \text { remedial design/remedial action } \\ \text { RDX } & \text { Royal Demolition Explosive } \\ \text { RI/FS } & \text { remedial investigation/feasibility study } \\ \text { ROD } & \text { Record of Decision } \\ \text { RTC } & \text { Reactor Technology Complex } \\ \text { SAM } & \text { Sample and Analysis Management } \\ \text { Sampling and analysis plan }\end{array}$


USC United States Code

UXO unexploded ordnance

WAG waste area group

WM wide-mouth 


\section{Field Sampling Plan for the Operable Units 6-05 and 10-04 Remedial Action, Phase IV}

\section{OVERVIEW}

The sampling and analysis plan (SAP) for the Idaho Cleanup Project (ICP) at the Idaho National Laboratory (INL) Waste Area Group (WAG) 10, Operable Units (OUs) 6-05 and 10-04, Phase IV remedial action comprises two parts:

1. Field sampling plan (FSP)

2. Quality Assurance Project Plan (QAPjP).

These plans have been prepared in accordance with 40 Code of Federal Regulations (CFR) 300, "National Oil and Hazardous Substances Pollution Contingency Plan"; guidance from the Environmental Protection Agency (EPA) on the preparation of SAPs; and "Environmental Sampling Activities at the INL" (MCP-9439). The FSP describes the field sampling activities that will be performed, while the QAPjP details the processes and programs that will be used to ensure that the data generated are suitable for their intended uses. The governing QAPjP for this sampling effort will be the Quality Assurance Project Plan for Waste Area Groups 1, 2, 3, 4, 5, 6, 7, 10, and Removal Actions (DOE-ID 2006a). This document is incorporated herein by reference. Work control processes will follow formal practices in accordance with the communicated agreement between the appropriate site area directors and the ICP Miscellaneous Sites area manager.

\subsection{Field Sampling Plan}

The remedial action for WAG 10 , OUs 6-05 and 10-04, is divided into four phases. Phase I consists of developing and implementing institutional controls at OU 10-04 sites and developing and implementing INL-wide plans for both institutional controls and ecological monitoring. The results of the Phase I remedial activities are documented in the Remedial Action Report for Operable Units 6-05 and 10-04, Phase I (DOE-ID 2005). The ecological monitoring requirements are delineated in the Long-Term Ecological Monitoring Plan for the Idaho National Engineering and Environmental Laboratory (INEEL 2004) with the INL Sitewide Institutional Controls Plan (DOE-ID 2006b) outlining the institutional control requirements.

The OU 10-04 Phase II addresses the remediation of sites contaminated with trinitrotoluene (TNT), Royal Demolition Explosive (RDX), and/or 1,3-dinitrotoluene, while Phase III will remediate lead contamination at the Security Training Facility (STF) - 02 gun range. The purpose of this FSP is to guide the collection and analysis of samples required to confirm that the remedial action objectives associated with the remediation of the Phase IV sites consisting of unexploded ordnance (UXO) -contaminated areas have been achieved. The project is being conducted in accordance with the requirements set forth in the Record of Decision Experimental Breeder Reactor-I/Boiling Water Reactor Experiment Area and Miscellaneous Sites, Operable Units 6-05 and 10-04 (DOE-ID 2002). 
Phase IV activities will require the removal or isolation of UXO found in areas within the INL followed by disposal of the UXO through high-order detonation. Five specific areas within the Naval Proving Ground (NPG) known to contain UXO include the following:

- $\quad$ Naval Ordnance Disposal Area (NODA)

- $\quad$ Mass Detonation Area (MDA)

- $\quad$ Experimental Field Station

- $\quad$ Rail Car Explosion Area

- $\quad$ Land Mine Fuze Burn Area.

\subsubsection{Field Sampling Objectives}

The primary focus of the remedial action is the recovery and disposal of UXO. If UXO must be disposed of in place by high-order detonation, it is expected that an area known as "kick-out" will be created. The "kick-out" area is expected to be circular in shape with a diameter of $30 \mathrm{ft}$ or less. The extent of the "kick-out" area will be determined by visual observation for shrapnel. The soil and "kick-out" area immediately surrounding the disposal location will be assessed to determine whether the disposal activities had an adverse impact resulting in an unacceptable risk to either human health or the environment from residual explosive contamination. If it is determined that explosive concentrations exceed risk-based levels, the impacted soils will be remediated followed by confirmation sampling to demonstrate that the remediation goals, as defined in the Record of Decision (ROD) (DOE-ID 2002), have been achieved. Following the completion of all disposal activities at the MDA, soil at the MDA will be sampled to determine whether an unacceptable risk remains as a result of residual explosive concentrations. This sampling will be followed by remediation, if necessary, and confirmation sampling.

\subsubsection{Other Documentation}

The Remedial Design/Remedial Action Work Plan for Operable Units 6-05 and 10-04, Phase IV (DOE-ID 2006c) outlines the activities required for remediation of the UXO-contaminated sites. The "Miscellaneous Sites Cleanup Project Health and Safety Plan" (PLN-2128) addresses the activities associated with remediation of the UXO-contaminated soil sites.

\subsection{Project Organization and Responsibility}

The organizational structure for this work reflects the resources and expertise required to plan and perform the work, while minimizing risks to worker health and safety. The Health and Safety Plan (HASP) (PLN-2128) defines the key project positions, lines of responsibility, and lines of communication for the project. The "Project Execution Plan for the Miscellaneous Sites Cleanup" (PLN-2087) and the "Roles and Responsibilities of the Miscellaneous Sites Personnel" (MCP-1432) detail the roles and responsibilities for project personnel. 


\section{SITE BACKGROUND}

\subsection{Site Description}

Located $51 \mathrm{~km}$ (32 mi) west of Idaho Falls, Idaho, the INL is a government-owned, contractor-operated facility managed by the Department of Energy Idaho Operations Office (DOE-ID) (Figure 2-1). Occupying 2,305 $\mathrm{km}^{2}\left(890 \mathrm{mi}^{2}\right)$ of the northeastern portion of the Eastern Snake River Plain, the INL encompasses portions of five Idaho counties: Butte, Jefferson, Bonneville, Clark, and Bingham.

As shown in Figure 2-2, WAG 10 is comprised of miscellaneous surface sites and liquid disposal areas throughout the INL that are not included within WAGs 1 through 9. Remedial action is required for five sites known to have UXO present. These sites include the NODA, the MDA, the Experimental Field Station, the Rail Car Explosion Area, and the Land Mine Fuze Burn Area. Figure 2-3 shows the location of these five sites within the NPG. The following sections describe the sites requiring remediation under Phase IV and are addressed in this FSP.

\subsubsection{Naval Ordnance Disposal Area}

The NODA site is located approximately $1.3 \mathrm{~km}(0.8 \mathrm{mi})$ northeast of U.S. Highway 20/26 between Mile Markers 265 and 266 and about $2.7 \mathrm{~km}(1.7 \mathrm{mi})$ southwest of the Reactor Technology Complex (RTC) (formerly the Test Reactor Area) at the INL, as shown in Figure 2-3. The NODA was reportedly used by the U.S. Navy as an ordnance and nonradioactive hazardous material disposal area during the 1940s. Following establishment of the National Reactor Testing Station in 1949 (now the INL), the NODA came under control of the Atomic Energy Commission (now the Department of Energy [DOE]). From about 1967 to 1985, approximately 3,175 $\mathrm{kg}(7,000 \mathrm{lb})$ of reactive material was treated (burned) at the NODA. Most of the reactive materials consisted of finely divided zirconium, hafnium, and zircaloy, which were openly burned and treated in disposal pits located at the NODA. No known disposal of radioactive materials occurred at the NODA and no evidence exists as to the contrary. Between 1967 and 1985, the NODA also was used as a storage area for hazardous waste generated at the INL. Solvents, corrosives, ignitable materials, heavy metal-contaminated solutions, formaldehyde, polychlorinated biphenyl materials, waste laboratory chemicals, and reactive materials were stored at this site until 1982. By October 1985, all these materials had been removed for off-Site disposal as hazardous waste or treated on-Site by open burning, as allowed by Resource Conservation and Recovery Act (RCRA) regulations (DOE-ID 1998; 42 USC $§ 6901$ et seq.).

In 1985, NODA was added to the RCRA, Part A, permit application as a thermal treatment unit. The last treatment of hazardous waste occurred in 1988 (except for one emergency action/detonation in 1990). Since 1988, activities necessary to formally close the NODA were initiated. These activities included soil sampling and analysis, removal of contaminated soil, emergency removal of ordnance, maintenance of access signs and barricades, and preparation and submittal of all required documentation. In 1997, the Idaho Department of Environmental Quality (DEQ) terminated the Interim Status of the NODA with the agreement that the Comprehensive Environmental Response, Compensation, and Liability Act (CERCLA) program would perform the final evaluation of the site in accordance with the Federal Facility Agreement and Consent Order for the Idaho National Engineering Laboratory (DOE-ID 1991).

The 1994 removal action included 16 ha (40 acres) centered approximately $762 \mathrm{~m}(2,500 \mathrm{ft})$ north of the current INL security force gun range on Portland Avenue (refer to Figure 2-4) as well as 90 acres within the Twin Buttes Bombing Range (refer to Figure 2-2) and Naval Gun Shells located east of Lincoln Boulevard within the Naval Proving Ground (refer to Figure 2-2) (DOE-ID 2001). The action identified UXO and explosive residue chunks using visual and geophysical scans and either destroyed 


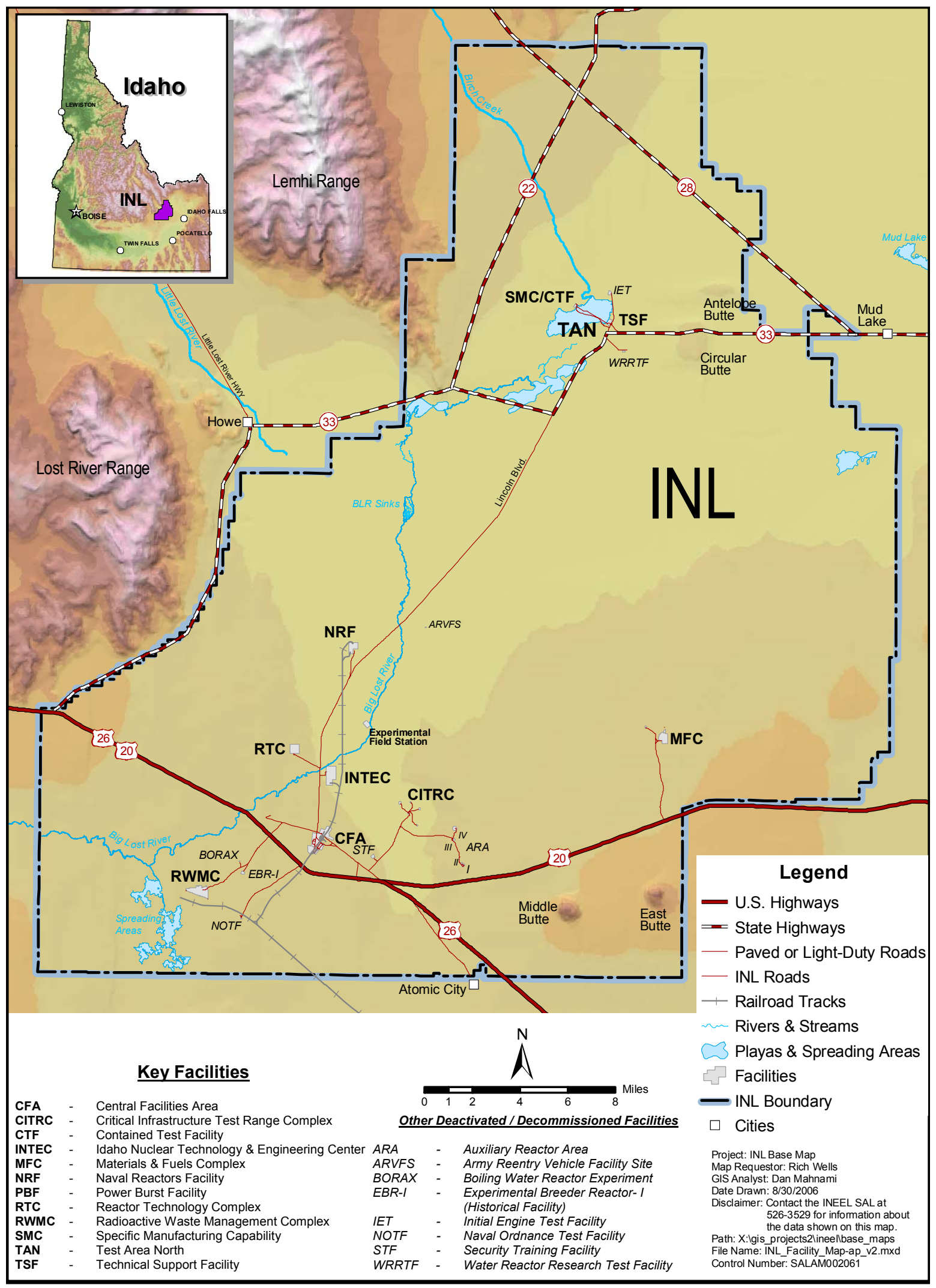

Figure 2-1. Idaho National Laboratory. 


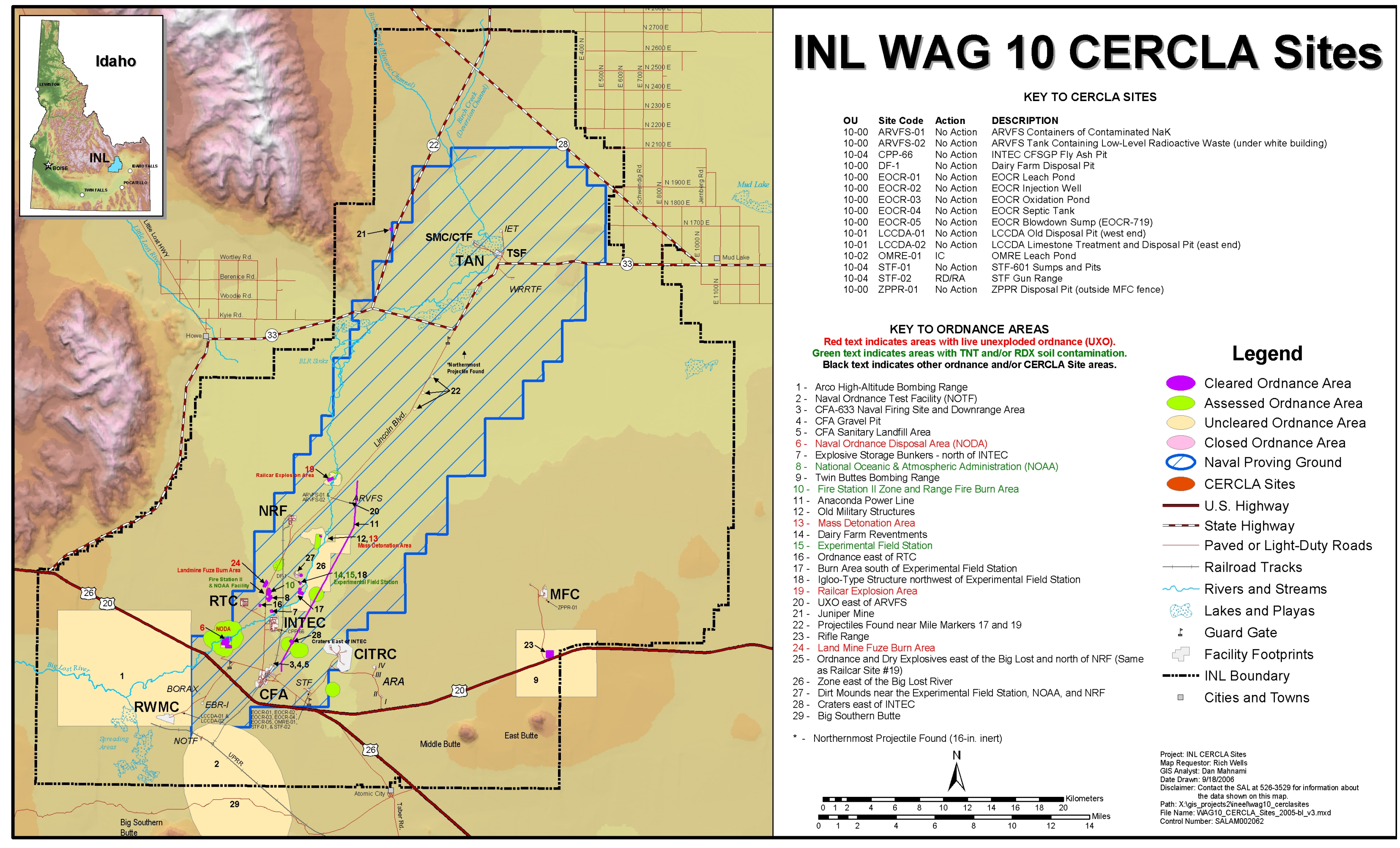




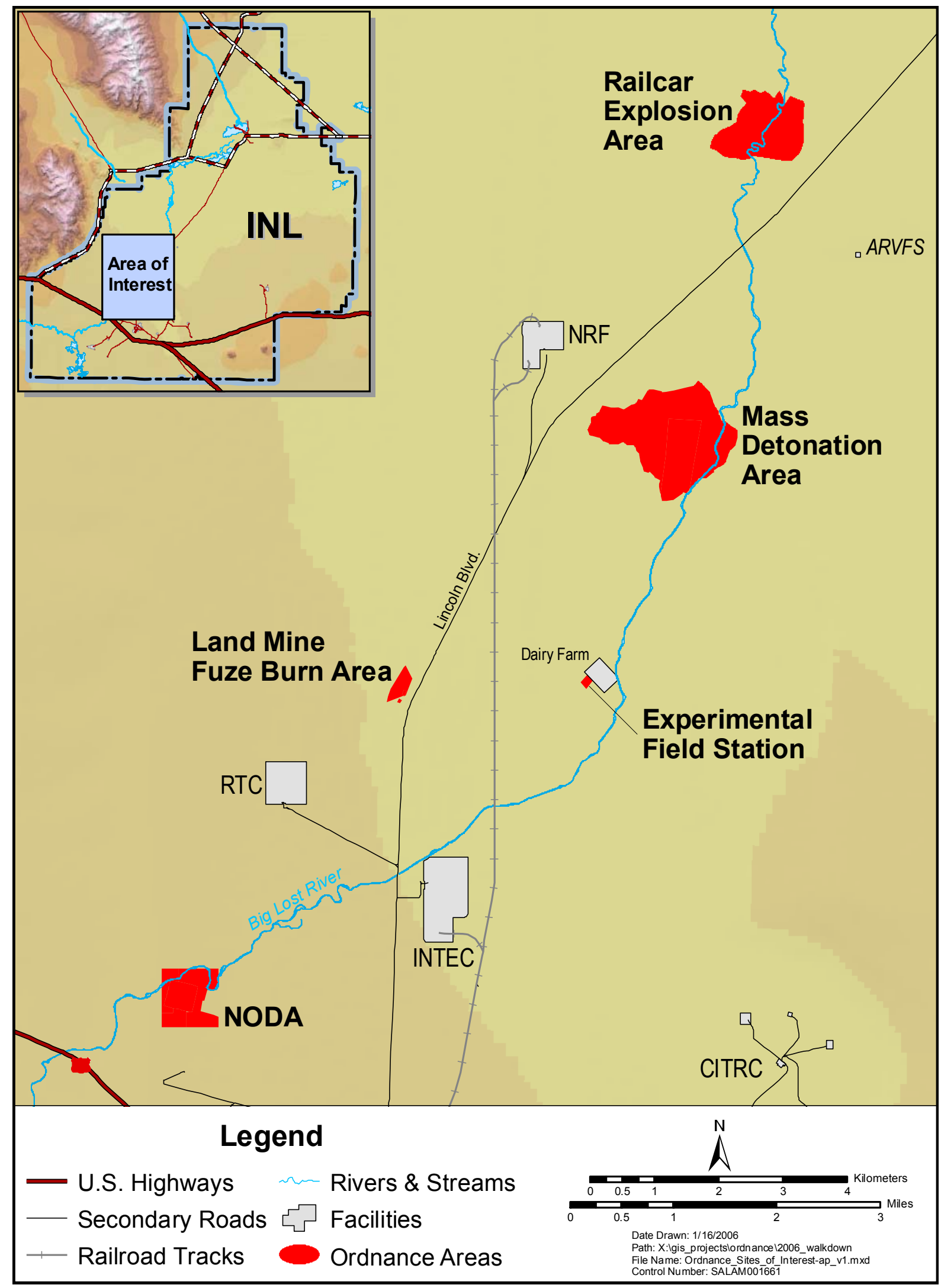

Figure 2-3. Location of the unexploded ordnance-contaminated sites. 


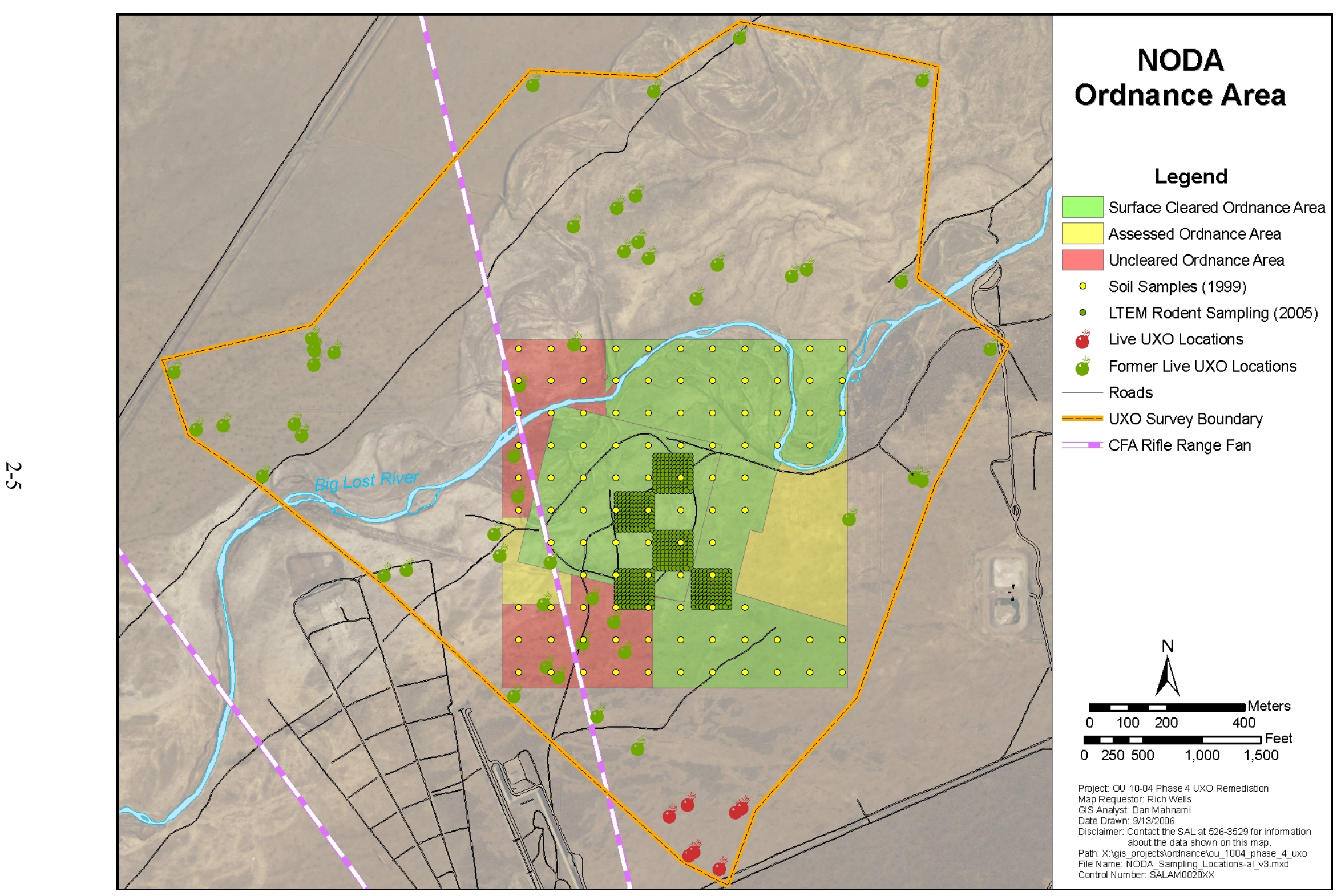

Figure 2-4. Naval Ordnance Disposal Area. 
them in place or removed them. The items removed during the 1994 and 1997 removal actions included fuzes, ordnance, and scrap metal, supporting the potential for these to continue to be present. More detailed information about the NODA site can be found in the Comprehensive Remedial Investigation/Feasibility Study for Waste Area Groups 6 and 10 Operable Unit 10-04 (DOE-ID 2001).

\subsubsection{Mass Detonation Area}

The MDA is located $0.6 \mathrm{~km}(0.4 \mathrm{mi})$ east of Mile Marker 8 on Lincoln Boulevard, north of the Idaho Nuclear Technology and Engineering Center (INTEC) and approximately $1.1 \mathrm{~km}(0.7 \mathrm{mi})$ east of the Naval Reactors Facility (NRF), as shown in Figure 2-3. The site encompasses 234.4 ha (579.1 acres) and has been used for a number of small- to large-scale sympathetic and mass detonation tests, with test shots ranging up to $226,800 \mathrm{~kg}(500,000 \mathrm{lb})$ of explosives. A sympathetic detonation test is a test performed to find out if a charge explodes when another charge is detonated next to it. The MDA site includes numerous blast craters varying in dimensions from a few feet to several tens of feet. Historically, large quantities of UXO, pieces of explosives, and structural debris scattered during past testing have been noted at the MDA. In addition, more recent disposal activities associated with previous removal actions, as well as explosive test activities, may have contributed to explosives contamination at the site. More detailed information pertaining to the MDA can be found in the OU 10-04 Comprehensive Remedial Investigation/Feasibility Study (RI/FS) (DOE-ID 2001).

\subsubsection{Experimental Field Station}

The Experimental Field Station includes multiple craters within which a variety of explosive tests were conducted. This site is located approximately $0.3 \mathrm{~km}(0.2 \mathrm{mi})$ west of the Big Lost River (see Figures 2-2 and 2-3). The site is an estimated 2 ha (5 acres) (DOE-ID 2001), although contamination resulting from UXO disposal is restricted to approximately $510 \mathrm{~m}^{2}\left(610 \mathrm{yd}^{2}\right)$ within the top $0.6 \mathrm{~m}(2 \mathrm{ft})$. The contamination does not pose human health risk above remediation goals but does pose a low ecological risk (DOE-ID 2002). The site is known to contain UXO, pieces of explosives, structural debris, and soil contamination. More detailed information about the Experimental Field Station can be found in the OU 10-04 Comprehensive RI/FS (DOE-ID 2001).

\subsubsection{Rail Car Explosion Area}

The Rail Car Explosion Area is located approximately $0.5 \mathrm{~km}(0.3 \mathrm{mi})$ due west of Mile Marker 12 on Lincoln Boulevard and adjacent to the Big Lost River channel, approximately $3.5 \mathrm{~km}$ (2.2 mi) northeast of the NRF, as shown in Figure 2-3. It encompasses approximately 115.7 ha (286 acres) and contains the debris scattered from a sympathetic detonation test involving five railroad cars, each loaded with $13,608 \mathrm{~kg}(30,000 \mathrm{lb})$ of explosive ordnance for a total of $68,040 \mathrm{~kg}(150,000 \mathrm{lb})$. The ordnance included, but was not limited to, 500-kg bombs loaded with Amatol and various Navy bombs loaded with TNT. The crater is located near the west bank of the Big Lost River, and pieces of ordnance and explosives (mostly RDX) historically have been located along both sides of the Big Lost River (DOE-ID 1998). The OU 10-04 Comprehensive RI/FS (DOE-ID 2001) provides additional information pertaining to the Rail Car Explosion Area.

\subsubsection{Land Mine Fuze Burn Area}

The Land Mine Fuze Burn Area is $125 \mathrm{~m}$ (410 ft) west of Lincoln Boulevard and approximately $0.24 \mathrm{~km}(0.15 \mathrm{mi})$ north of the Fire Station II training area (Mile Marker 5) (see Figure 2-3). The site consists of approximately five separate ordnance disposal locations in a 10.7-ha (26-acre) area between a meander of a former Big Lost River channel and an old abandoned irrigation canal that was hand-dug in the early 1900s (DOE-ID 2001). Based upon visual observation, the UXO-contaminated area of the site 
is restricted to a few square meters in a single location. As described in the Preliminary Scoping Track 2 Summary Report for Operable Unit 10-03 Ordnance (DOE-ID 1998), the site was used by NPG personnel for disposal of land mine pressure plates and aerial bomb packaging materials and as an area to dispose of land mine fuzes by burning. Although previous removal actions were performed at the Land Mine Fuze Burn Area in 1996 and 1997, additional land mine fuzes are likely to be present. More detailed information about the Land Mine Fuze Burn Area can be found in the OU 10-04 Comprehensive RI/FS (DOE-ID 2001).

\subsection{Nature and Extent of Contamination}

Remedial action is required for the NODA, the MDA, Experimental Field Station, the Rail Car Explosion Area, and the Land Mine Fuze Burn Area. The following subsections provide a brief description of the nature and extent of contamination at the five sites that require remediation. Detailed information about the individual sites can be found in the OU 10-04 Comprehensive RI/FS (DOE-ID 2001).

\subsubsection{Naval Ordnance Disposal Area}

Historically, this area was used by the Navy as a disposal area and experimental site. Activities deposited pieces of explosive compounds, ordnance, and ordnance components over the site. Previous removal actions addressing the NODA have included the 1994 non-time-critical removal action, the 1997 non-time-critical removal action, and the 2004 time-critical removal action.

During the 1994 non-time-critical removal action, a total of 461 suspected pieces of ordnance were marked and logged, with 1,400 lb destroyed by high-order detonation. In addition, $2 \mathrm{lb}$ of TNT and $10 \mathrm{lb}$ of RDX were removed and destroyed. The ordnance consisted primarily of fuzes and small projectiles, with small quantities of booster cups, tracers, projectile base plates with tracers, and an igniter. An additional $32,850 \mathrm{lb}$ of ordnance-related debris were recovered and shipped to the Central Facilities Area (CFA) landfill for disposal. The non-time-critical removal action continued into 1995, during which time 462 pieces of UXO and $18 \mathrm{lb}$ of bulk high explosives were disposed of through high-order detonation and 39,470 $\mathrm{lb}$ of metal fragments were sent to the landfill.

The 1997 non-time-critical removal action resulted in the recovery of 107 pieces of ordnance, $14,798 \mathrm{lb}$ of ordnance-related scrap, and $159 \mathrm{lb}$ of non-ordnance-related scrap. The ordnance recovered was similar to that recovered during the 1994 action. During the 2004 time-critical removal action, a total of 11 fuzes and fifty-one 5-in. antiaircraft common rounds were recovered and disposed of by high-order detonation at the MDA.

Figure 2-4 depicts the cleared, assessed, and uncleared ordnance areas at the NODA site. A cleared area is one in which the area has been surveyed for ordnance and any ordnance found has been removed and disposed of by high-order detonation. An assessed area is one in which the area has been surveyed for ordnance and there is a potential of live ordnance remaining in the area based upon evidence of ordnance (e.g., fragments) even though none was previously found and removed. An uncleared area has not been surveyed and no action has been taken to remove any ordnance from the area. The figure provides the locations where samples were collected in support of the OU 10-04 Comprehensive RI/FS. The inert UXO and fragments shown on the map consist primarily of fragments and are currently known to be present at the site. The former live UXO locations represent the UXO that was retrieved in support of the 2004 time-critical removal action. During the 2005 long-term ecological monitoring effort, five plots were laid out at the NODA for trapping small mammals. No UXO was encountered within these plot areas shown in Figure 2-4, thereby supporting the assumption that previous removal actions conducted at NODA have been successful in recovering UXO at the site. 


\subsubsection{Mass Detonation Area}

Historically, the MDA was used by the Army and Navy to conduct large-scale detonation tests in the 1945 to 1946 timeframe. The tests involved the detonation of explosive-filled magazines containing up to 500,000 lb of explosive ordnance. The purpose of most of the magazine tests was to determine if larger quantities of explosives could be stored in magazines without initiating adjacent magazines. Additionally, there were two sites where $250,000 \mathrm{lb}$ of TNT in land mines were detonated in open revetments. The area has more recently been used as a disposal site for explosives and UXO by high-order detonation.

During the 1993 interim action, five pieces of UXO were recovered and disposed of by detonation. During the 1996 Track 2 field assessment, one antitank mine still in the shipping crate, one live tetryl bomb booster, five empty 40-mm cartridges with live primers, and several inert projectile fuzes were found. Again, these items were disposed of by detonation. The 1997 non-time-critical removal action addressed the remediation of this area during which five pieces of UXO were recovered and disposed of by detonation and $0.25 \mathrm{lb}$ of high explosives and over $8,600 \mathrm{lb}$ of metal scrap were removed.

Unfortunately, the locations of the UXO identified in 1993, 1996, and 1997 were not recorded and, as a result, cannot be shown on a map of the area.

Figure 2-5 depicts the MDA, delineating the cleared, assessed, and uncleared ordnance areas at the site. A cleared area is one in which the area has been surveyed for ordnance and any ordnance found has been removed and disposed of by high-order detonation. An assessed area is one in which the area has been surveyed for ordnance and there is a potential of live ordnance remaining in the area based upon evidence of ordnance (e.g., fragments) even though none was previously found and removed. An uncleared area has not been surveyed and no action has been taken to remove any ordnance from the area. The figure provides the locations where samples were collected in support of the OU 10-04 RI/FS. During the 2004 long-term ecological monitoring effort, 10 plots were laid out at the MDA for trapping small mammals, with land mine base fuzes encountered in one of the plots.

\subsubsection{Experimental Field Station}

During the 1996 Track 2 field assessment, a 0.81-ha (2-acre) area was identified as requiring surface clearance because of scattered pieces of explosives and stained soil (DOE-ID 1998). A second area of approximately 0.8 acres was mapped that contained heavy concentrations of TNT-contaminated soil. This was the area recommended for the treatability study discussed in Section 3.2.2 of the Phase IV Remedial Design/Remedial Action (RD/RA) Work Plan (DOE-ID 2006c). The assessment included a visual search for signs of craters, detonation tests, surface UXO, pieces of explosives, and soil contamination. When TNT was encountered, the area was examined in greater detail and mapped. No ordnance was found in any of the craters, which appeared to have resulted from ordnance destruction or ordnance testing. Approximately $1.5 \mathrm{mi}$ away, the nose section of a World War I vintage bomb (as identified by an explosives ordnance disposal expert based upon review of military ordnance manuals) with TNT and an empty tail section was found and disposed of by detonation at the MDA during the 1996 removal action. It is unclear why World War I vintage ordnance would be present at the site. Conjecture would lead one to believe that the Navy would use older ordnance for tests performed at the NPG rather than use ordnance with a useful life given the timeframe during which naval operations occurred at the site. No other UXO was found at this site during the 1996 removal action or Track 2 field assessment.

The area was addressed during the 1997 non-time-critical removal action during which $55 \mathrm{lb}$ of bulk high explosives were recovered and disposed of by high-order detonation. In addition, $660 \mathrm{lb}$ of ordnance-related scrap and $100 \mathrm{lb}$ of non-ordnance-related scrap were recovered and disposed of. 


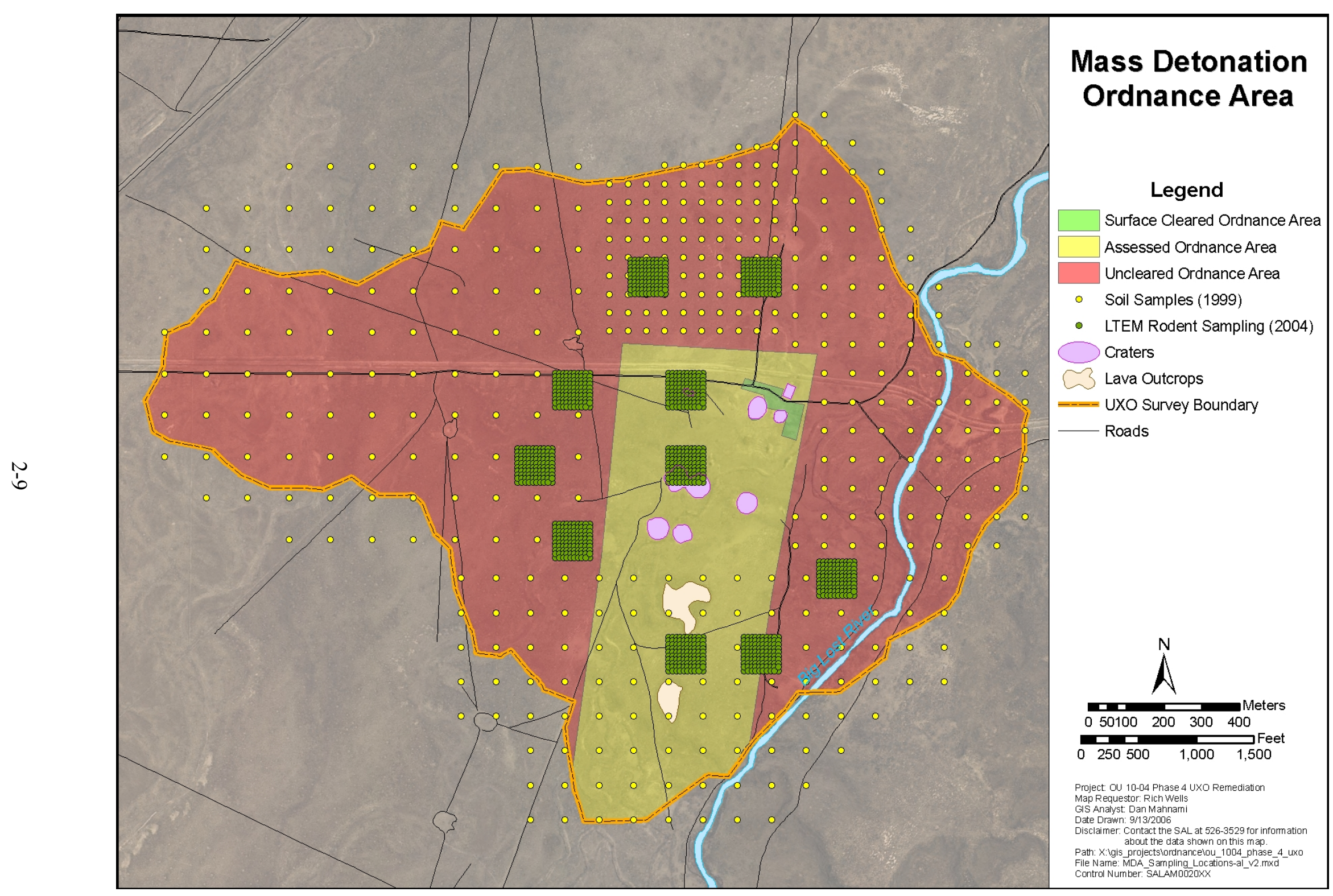

Figure 2-5. Mass Detonation Area. 
Figure 2-6 depicts the Experimental Field Station, delineating the cleared and uncleared ordnance areas at the site. The figure also provides the locations where samples were collected in support of the OU 10-04 RI/FS in 1999. The inert UXO and fragments shown on the map consist primarily of fragments and are currently known to be present at the site. During the 2003 long-term ecological monitoring effort, one plot was laid out at the Experimental Field Station for trapping small mammals. No UXO was encountered within this plot area shown in Figure 2-6, thereby supporting the assertion that a minimum number of UXO-related items are located at the site.

\subsubsection{Rail Car Explosion Area}

Ordnance and explosives contamination at the Rail Car Explosion Area originated from a test conducted in which five rail cars, each with $30,000 \mathrm{lb}$ of explosives, were detonated on August 31, 1945, to determine the missile distance and hazard that could be expected if a loaded ammunition train detonated. The rail cars were placed in line on a short stretch of track and all 150,000 lb of explosives were detonated simultaneously when the center car was initiated. During the 1996 time-critical removal action, a visual sweep and geophysical survey were performed at the site. In all, a total of 429 anomalies identified during the geophysical survey were investigated using hand-digging techniques, with over 4,250 lb of inert materials, including rail car components and ordnance residue, being removed from the site. Three live 5-in. projectiles were found during the 1996 removal action and transported to the MDA, along with $25 \mathrm{lb}$ of bulk explosive for disposal by detonation.

During the 1997 non-time-critical removal action, a total of $0.56 \mathrm{lb}$ of high explosives was recovered and disposed of by detonation. In addition, 2,159 lb of ordnance-related scrap and 10,135 $\mathrm{lb}$ of non-ordnance-related scrap were recovered and disposed of.

Figure 2-7 depicts the Rail Car Explosion Area, delineating the cleared, assessed, and uncleared ordnance areas at the site. A cleared area is one in which the area has been surveyed for ordnance and any ordnance found has been removed and disposed of by high-order detonation. An assessed area is one in which the area has been surveyed for ordnance and there is a potential of live ordnance remaining in the area based upon evidence of ordnance (e.g., fragments) even though none was previously found and removed. An uncleared area has not been surveyed and no action has been taken to remove any ordnance from the area. The figure provides the locations where samples were collected in support of the OU 10-04 $\mathrm{RI} / \mathrm{FS}$. The inert UXO and fragments shown on the map consist primarily of fragments that are currently known to be present at the site. The live UXO location represents several cracked open shells with base fuzes that are still located in and around a crater within the Rail Car Explosion Area. During the 2005 long-term ecological monitoring effort, five plots were laid out at the Rail Car Explosion Area for trapping small mammals. The presence of the shells was confirmed during the 2005 ecological monitoring activities. The shells were visually identified as 5-in. projectiles, similar to those that have been located and removed during previous removal actions.

\subsubsection{Land Mine Fuze Burn Area}

Historically, the Land Mine Fuze Burn Area appears to have been a demilitarization and disposal area for land mine fuzes. Most of the land mine fuzes that have been found show evidence of having been burned. However, some did not show any evidence of exposure to fire and appeared to be undamaged. During the 1996 time-critical removal action, a visual surface sweep was performed of the area along with a geophysical survey to locate and remove surface and near-surface metallic objects. A total of 1,018 individual fuzes were removed, of which 118 contained explosives. Additionally, a total of over $36,000 \mathrm{lb}$ of scrap and approximately $60 \mathrm{lb}$ of raw explosive also were removed from the area. Inert scrap found and removed consisted primarily of pressure plates, bomb-packaging materials, and inert mine fuze bodies. 


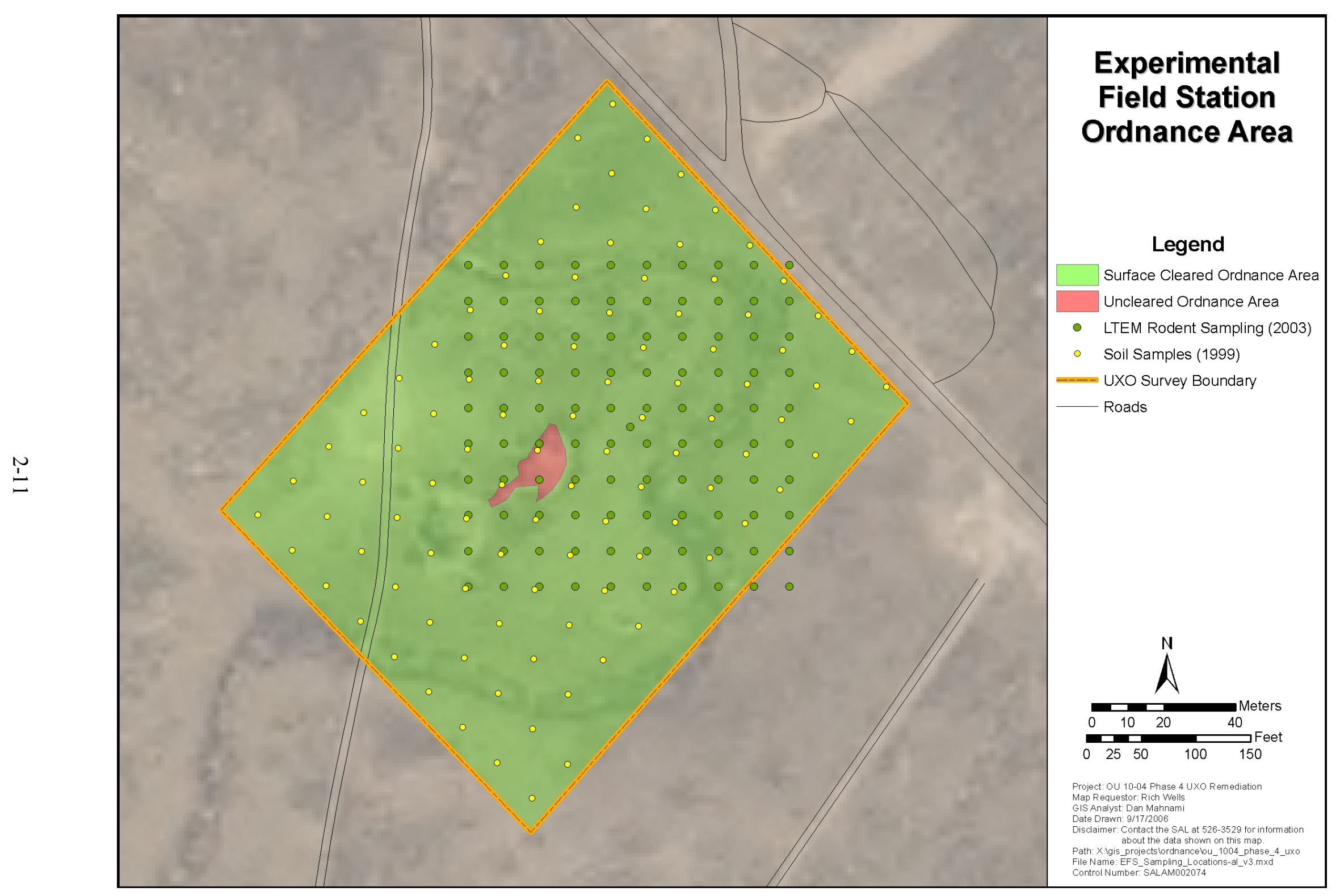

Figure 2-6. Experimental Field Station. 


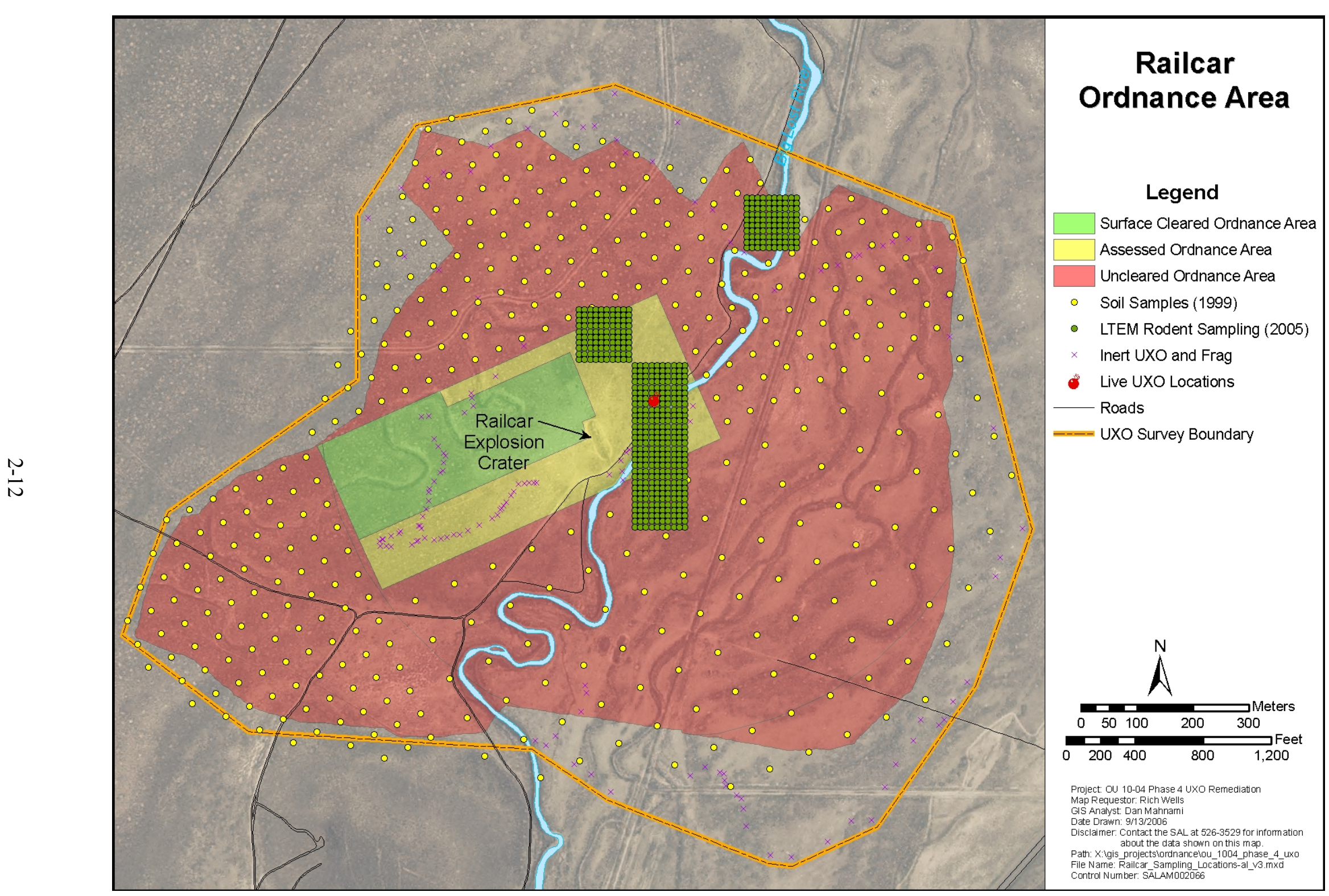

Figure 2-7. Rail Car Explosion Area. 
During the 1997 non-time-critical removal action, 28 UXO-related items consisting of M1A2 mines were recovered and disposed of by detonation. In addition, 2,830 lb of ordnance-related scrap were recovered and disposed of.

Figure 2-8 depicts the Land Mine Fuze Burn Area delineating the cleared, assessed, and uncleared ordnance areas at the site. The figure also provides the locations where samples were collected in support of the OU 10-04 RI/FS. The inert UXO and fragments shown on the map consist primarily of fragments that are currently known to be present at the site. The former live UXO locations represent a number of fuzes still located in the area.

\subsection{Project Description}

Based on consideration of the CERCLA requirements, the detailed analysis of alternatives, and public comments, the Agencies (i.e., DOE, DEQ, and EPA) have chosen UXO detection, removal, and institutional controls as the remedy for the UXO-contaminated sites at OU 10-04. Performance standards were implemented as design criteria to ensure that the selected remedy protects human health and the environment. Five-year reviews will be used to ensure that the selected remedy remains protective and appropriate.

\subsubsection{Contaminated Soil Sites}

The remediation of the ordnance areas will be performed in accordance with the requirements outlined in the Phase IV RD/RA Work Plan (DOE-ID 2006c) and will include the following activities:

- Institutional controls, which were implemented during the OU 10-04 Phase I activities, will be maintained until the UXO hazard is removed or reduced to levels acceptable for current and anticipated future land use. The specific goals of the institutional controls are to control human activity at sites with suspected UXO contamination and prevent harm from unintentional detonation of UXO.

- The boundaries of the UXO impacted areas have been defined based upon the results of previous removal actions.

- Visual and geophysical surveys will be performed to detect the presence of UXO.

- $\quad$ Potential UXO targets will be investigated during the survey.

- The ordnance density, explosive characteristics of UXO, and ordnance accessibility will be determined.

- The relative risks of land use based on the type, amount, and accessibility of UXO will be determined as well as the extent of UXO removal required to meet desired land use objectives.

- The UXO will be recovered and transported to the MDA for disposal by detonation. If it is determined that the UXO cannot be safely recovered, it will be disposed of by detonation in place. Waste generated as a result of the detonation activities will be addressed according to current disposal practices. 


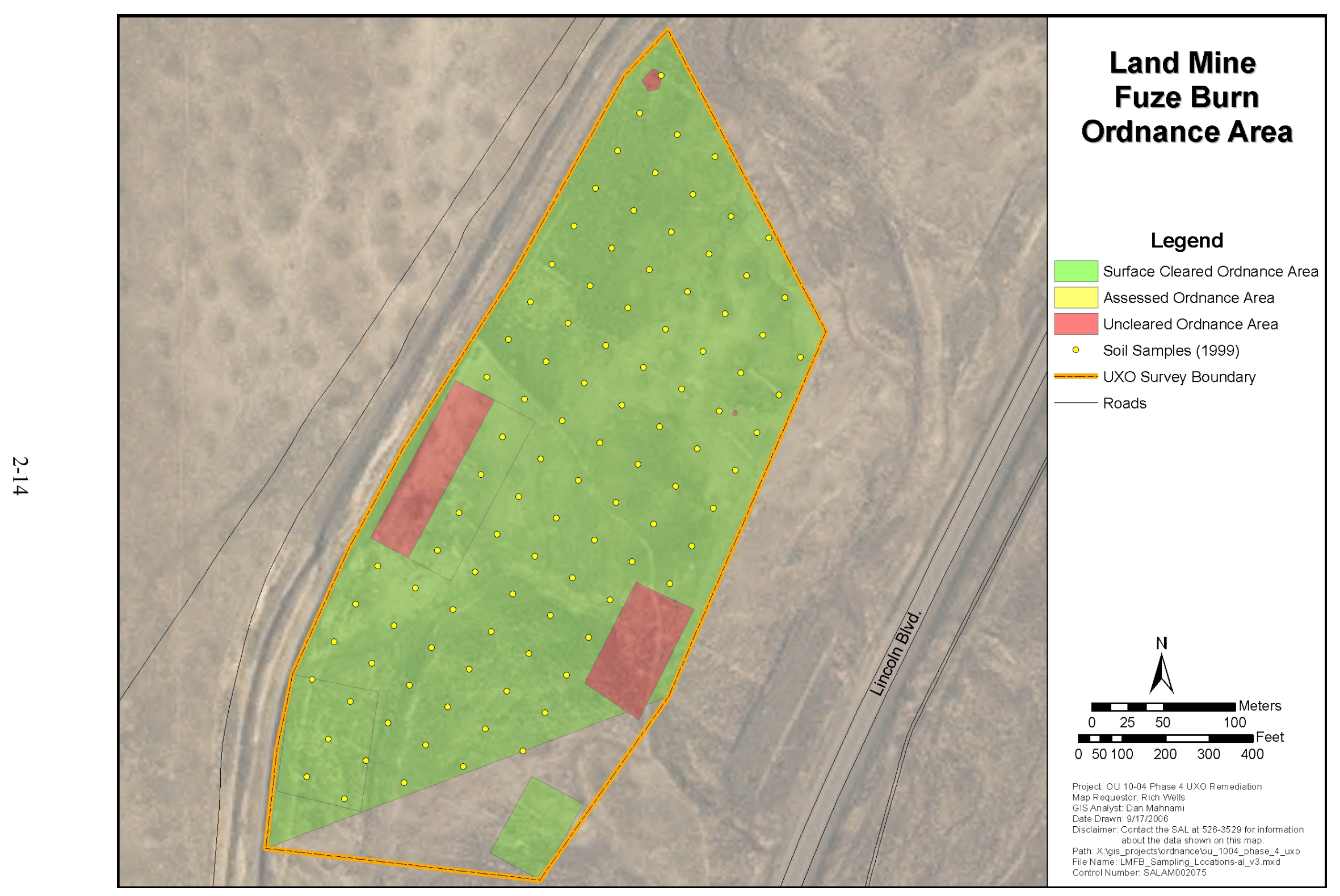

Figure 2-8. Land Mine Fuze Burn Area. 
- $\quad$ Other recovered non-ordnance items, such as shrapnel, will be disposed of at the CFA landfill or sent off-Site for recycling. If secondary explosive contamination (such as TNT or RDX) is discovered, the impacted area will be remediated in accordance with the ROD (DOE-ID 2002).

- $\quad$ Areas excavated deeper than $1 \mathrm{ft}$ will be backfilled and contoured to match the surrounding terrain, as appropriate, and revegetated with native species.

Geophysical surveys will be conducted over the ordnance areas defined in the Phase IV RD/RA Work Plan (DOE-ID 2006c) to identify potential UXO. Anomalies detected from the surveys will be noted and further investigated to determine whether intrusive investigation is required to remove suspect items. Any items removed that could be UXO will be detonated at the MDA, unless it is determined that removing the items poses an unacceptable risk to personnel, in which case the UXO will be detonated in place. Detonation of UXO will be performed in a manner that does not threaten human health or the environment and meets the minimum distance to property of others as specified in the RCRA "Open Burning: Waste Explosives" regulation. Sampling will be performed to determine if products of incomplete combustion are present after detonation events at the MDA (or other areas where UXO is detonated). For areas other than the MDA, sampling will occur immediately following the disposal activity to determine whether the soils have been adversely impacted. Although detectable levels are not expected, remediation of soil contamination of impacted soils will be performed if residual risk exceeds 1E-04. Therefore, the MDA will be investigated for remediation following the completion of all remediation activities at other UXO- and TNT/RDX-contaminated sites. Other non-UXO items recovered, such as shrapnel, will be disposed of at the CFA landfill or sent off-Site for recycling.

Geophysical investigations for buried munitions are seldom $100 \%$ effective. In many cases, a munition is buried too deep, is too small to be detected, or is constructed of a material difficult to detect. Later, through frost heave, erosion, or construction, the item can reach the surface. In addition, because the total amount of munitions buried at a site is almost never known, complete recovery cannot be documented. Therefore, periodic surveys might be required and established institutional controls will be maintained.

Institutional controls will be maintained at the ordnance areas until the UXO hazard is removed or reduced to acceptable levels. Controls are required to restrain human activity at areas with suspected UXO contamination and prevent harm from unintentional detonation of UXO. In April 1999, the EPA Region 10 developed a policy for institutional controls. In accordance with those requirements, the INL Sitewide Institutional Controls Plan (DOE-ID 2006b) was developed along with the Operations and Maintenance Plan for Operable Units 6-05 and 10-04, Phase II (DOE-ID 2004), which provides institutional control and operations and maintenance requirements specific to OU 10-04 sites.

Access to the INL is currently restricted for purposes of security and public safety. Sitewide access restrictions limit accessibility until at least 2095 based on the Idaho National Laboratory Comprehensive Land Use and Environmental Stewardship Report (INL 2005) for ordnance areas within the INL boundary. Other access control measures include warning signs, assessing trespassing fines, and training requirements for persons allowed access. Land-use restrictions will be specified if government control of the INL is not maintained throughout the institutional control period. 


\section{SAMPLING DATA QUALITY OBJECTIVES}

Data needs and data quality objectives (DQOs) for conducting the proposed sampling in support of the remedial action activities for the individual sites are defined in the following sections. Data needs have been determined through the evaluation of existing data and the projection of data requirements for the analysis of samples collected during the Phase IV remedial action. The DQOs have been developed following the process outlined in Guidance for the Data Quality Objectives Process (EPA 1994).

\subsection{Problem Statement}

The first step in the DQO process is to state the problem to be addressed and to put it in programmatic context. There are four basic parts of the problem: (1) contamination assessment, (2) soil excavation, (3) waste designation, and (4) confirmation that the remedial action objectives have been achieved. Contamination assessment addresses the determination as to whether soil at the 200 -ft crater in the MDA or at other locations where UXO has been detonated in place poses an unacceptable risk to human health or the environment. Separate problem statements are provided for the MDA versus other locations because of the extent of contamination anticipated. Larger disposal detonations have historically taken place at the MDA presumably resulting in a larger spread of contamination. Several pieces of ordnance would be grouped at one time for disposal at the MDA by a single high-order detonation. Similarly, disposal activities conducted at the MDA in support of this Phase IV remedial action will involve several pieces of UXO being disposed of at one time. By comparison, disposal in place will involve the detonation of a single piece of UXO that cannot be safely recovered with sand bags emplaced around it to minimize the impact on the surrounding area. Soil excavation addresses the field input to guide excavation locations and minimize soil removal. Waste designation addresses whether the excavated soil may be characteristic. Confirmation addresses soil remaining in place.

The problem statements associated with the DQO process are as follows:

- $\quad$ Problem Statement 1a-Given that soil at the 200-ft crater in the MDA may be adversely impacted by UXO and TNT/RDX disposal operations, collect analytical data to determine whether soil poses an unacceptable risk to human health or the environment.

- $\quad$ Problem Statement 1b - Given that soil at a site may be adversely impacted by in-place UXO detonation and disposal, collect analytical data to determine whether soil poses an unacceptable risk to human health or the environment.

- $\quad$ Problem Statement 2 - Given that soil determined to pose an unacceptable risk needs to be excavated and disposed of, collect near-real-time data for TNT and/or RDX, as appropriate, to guide excavation locations and minimize soil disposal.

- $\quad$ Problem Statement 3 - Given that the toxicity characteristic leaching procedure (TCLP) concentration for explosives and explosive residues in excavated soil potentially exceeds the regulatory level, collect characterization data required to determine whether excavated soil requires stabilization prior to disposal.

- $\quad$ Problem Statement 4a-Given that soil remains in place at the 200-ft crater in the MDA, collect the confirmation data required to demonstrate that the remedial action objectives specified in the ROD (DOE-ID 2002) for TNT, RDX, and 1,3-dinitrobenzene have been achieved. 
- Problem Statement $\mathbf{4 b}$ - Given that soil remains in place at a site where UXO was detonated and disposed of in place, collect the confirmation data required to demonstrate that the remedial action objectives specified in the ROD (DOE-ID 2002) for TNT, RDX, and 1,3-dinitrobenzene have been achieved.

\subsection{Decision Identification}

The purpose of DQO Step 2 is to define the principal study questions (PSQs) that need to be resolved to address the problem statements identified in DQO Step 1 and the alternative actions that would result from resolution of the PSQs. The PSQs and the associated alternative actions were combined into decision statements (DSs). The PSQs and resultant DSs are as follows:

- PSQ 1a and 1b-Do the soils at the MDA or any site where UXO is disposed of in place by detonation pose an unacceptable risk to human health or the environment?

- DS 1a and 1b-Determine the explosive contamination concentrations in the impacted soils.

- $\quad$ PSQ 2-How far and where should the excavation be carried out?

- DS 2-Determine the extent of initial excavation and subsequent hot spot excavations.

- $\quad$ PSQ 3 - Is excavated soil from any site RCRA-characteristic?

- DS 3-Determine the TCLP concentrations for explosives and explosive by-products.

- PSQ 4a and $4 \mathbf{b}$ - Does the soil remaining after excavation meet site remedial action goals?

- $\quad$ DS 4a and $4 b$-Determine whether soil remaining after remediation meets site remedial action goals as specified in the ROD (DOE-ID 2002), and determine whether remediation is complete, as defined in Section 3.7.3 or 3.7.4, as appropriate.

\subsection{Decision Inputs}

The purpose of DQO Step 3 is to identify the type of data needed to resolve each of the DSs identified in DQO Step 2. These data may already exist or may be derived from computational or surveying/sampling and analysis methods. Analytical performance requirements (e.g., practical quantitation limit [PQL] requirement, precision, and accuracy) also are provided in this step for any new data that need to be collected.

\subsubsection{Information Required to Resolve Decision Statements}

It is necessary to determine the information (data) required to resolve each of the DSs identified in Section 3.2 and identify whether these data already exist. For the large crater located at the MDA and any other site where UXO is disposed of by detonation in place, data for concentrations of explosives are needed to address DSs $1 \mathrm{a}$ and $1 \mathrm{~b}$. For areas requiring excavation, near-real-time TNT and/or RDX data are required, as appropriate, to address DS 2. For excavated soils, TCLP concentrations for explosives and explosive by-products are required to determine whether the excavated soils are characteristic in addressing DS 3, thus requiring stabilization prior to disposal. For any areas where excavation has occurred, concentrations of explosives are required to satisfy DSs $4 \mathrm{a}$ and $4 \mathrm{~b}$.

The data acquired to satisfy DSs 1a, 1b, 4a, and $4 \mathrm{~b}$ will consist of laboratory measurements for contaminants of concern (COCs). For DS 2, the data will be comprised of field-screening measurements to provide near-real-time direction for site excavation. For DS 3, concentrations of explosives will be determined by TCLP laboratory analysis. Data for DS 2 are required to estimate the horizontal and 
vertical extent of contamination to aid in the removal action, and data for DSs $4 \mathrm{a}$ and $4 \mathrm{~b}$ are required of the remaining soil to demonstrate that the remedial action objectives have been achieved.

\subsubsection{Basis for Setting the Action Level}

The action level is the threshold value that provides the criterion for choosing between alternative actions. The basis for setting the action level for DSs $1 \mathrm{a}, 1 \mathrm{~b}, 2,4 \mathrm{a}$, and $4 \mathrm{~b}$ is the potential for exceeding human health and/or ecological risk-based concentrations in the contaminated soil. For DS 3, the action level is the toxicity characteristic regulatory concentration as defined in 40 CFR 261.24, "Toxicity Characteristic." The numerical values of the action levels are defined in DQO Step 5.

\subsubsection{Computational and Survey/Analytical Methods}

Table 3-1 identifies the DSs where existing data either do not exist or are of insufficient quality to resolve the DSs. In addition, Table 3-1 presents computational and surveying/sampling methods that could be used to obtain the required data.

- DSs 1a and 4a-A statistically based number of samples will be collected from which the $95 \%$ upper confidence limit (UCL) of the mean will be compared to the remedial action goals, as defined in the ROD (DOE-ID 2002).

- $\quad$ DSs $1 \mathbf{b}$ and $4 \mathbf{b}$ - Three composites of field samples will be collected from which the maximum concentration will be compared to the remedial action goals, as defined in the ROD (DOE-ID 2002). Composites will be used rather than a statistically based number of samples because of the relatively small area anticipated to require remediation.

- DS 2-Field-screening samples will be collected for the contaminants in order to estimate the horizontal and vertical distribution of the COCs exceeding the remedial action goals during the remedial action.

- $\quad$ DS 3-Samples will be collected for TCLP analysis from the excavated soils to determine whether they are characteristic for the given contaminants.

Table 3-1. Information required to resolve the decision statements.

\begin{tabular}{|c|c|c|c|}
\hline DS & Required Data & Computational Methods & $\begin{array}{c}\text { Survey/Analytical Methods for } \\
\text { Determination of Contaminant } \\
\text { Concentrations in Soil }\end{array}$ \\
\hline $1 \mathrm{a}$ and $4 \mathrm{a}$ & $\begin{array}{l}\text { Chemical } \\
\text { concentrations in soil }\end{array}$ & $\begin{array}{l}\text { Compare mean ( } 95 \% \text { UCL) to } \\
\text { remedial action goals }\end{array}$ & Laboratory analysis \\
\hline $1 b$ and $4 b$ & $\begin{array}{l}\text { Chemical } \\
\text { concentrations in soil }\end{array}$ & $\begin{array}{l}\text { Compare analytical result to } \\
\text { remedial action goals }\end{array}$ & Laboratory analysis \\
\hline 2 & $\begin{array}{l}\text { Chemical } \\
\text { concentrations and } \\
\text { extent of contamination }\end{array}$ & Field-screening measurements & Field test kits \\
\hline 3 & $\begin{array}{l}\text { TCLP concentrations in } \\
\text { soil }\end{array}$ & $\begin{array}{l}\text { Compare results to contaminant } \\
\text { concentrations for the toxicity } \\
\text { characteristic }\end{array}$ & Laboratory analysis \\
\hline \multicolumn{4}{|c|}{$\begin{array}{l}\text { DS }=\text { decision statement. } \\
\text { TCLP = toxicity characteristic leaching procedure. } \\
\text { UCL = upper confidence limit. }\end{array}$} \\
\hline
\end{tabular}




\subsubsection{Analytical Performance Requirements}

Table 3-2 defines the analytical performance requirements for the data that need to be collected to resolve each DS. These performance requirements include the PQL and precision and accuracy requirements for each $\mathrm{COC}$.

Table 3-2. Analytical performance requirements.

\begin{tabular}{|c|c|c|c|c|c|c|}
\hline DS & $\begin{array}{c}\text { Target } \\
\text { Analyte List }\end{array}$ & $\begin{array}{c}\text { Survey/Analytical } \\
\text { Methods }\end{array}$ & $\begin{array}{c}\text { Preliminary } \\
\text { Action Level } \\
\end{array}$ & PQL & $\begin{array}{c}\text { Precision } \\
\text { Requirement }\end{array}$ & $\begin{array}{c}\text { Accuracy } \\
\text { Requirement } \\
(\%)\end{array}$ \\
\hline \multirow[t]{4}{*}{$1 \mathrm{a}$} & 1,3-DNB & SW-846 Method 8330 & $6.1 \mathrm{mg} / \mathrm{kg}$ & $0.25 \mathrm{mg} / \mathrm{kg}$ & $\pm 15 \%$ & $60-120$ \\
\hline & $\mathrm{RDX}$ & & $4.4 \mathrm{mg} / \mathrm{kg}$ & $1.0 \mathrm{mg} / \mathrm{kg}$ & & \\
\hline & TNT & & $16 \mathrm{mg} / \mathrm{kg}$ & $0.25 \mathrm{mg} / \mathrm{kg}$ & & \\
\hline & PETN & & TBD & $0.25 \mathrm{mg} / \mathrm{kg}$ & & \\
\hline \multirow[t]{4}{*}{$1 \mathrm{~b}$} & 1,3-DNB & SW-846 Method 8330 & $6.1 \mathrm{mg} / \mathrm{kg}$ & $0.25 \mathrm{mg} / \mathrm{kg}$ & $\pm 15 \%$ & $60-120$ \\
\hline & RDX & & $4.4 \mathrm{mg} / \mathrm{kg}$ & $1.0 \mathrm{mg} / \mathrm{kg}$ & & \\
\hline & TNT & & $16 \mathrm{mg} / \mathrm{kg}$ & $0.25 \mathrm{mg} / \mathrm{kg}$ & & \\
\hline & PETN & & TBD & $0.25 \mathrm{mg} / \mathrm{kg}$ & & \\
\hline \multirow[t]{2}{*}{2} & $\mathrm{RDX}$ & SW-846 Method 8510 & $4.4 \mathrm{mg} / \mathrm{kg}$ & $0.8 \mathrm{mg} / \mathrm{kg}$ & $\pm 15 \%$ & $60-120$ \\
\hline & TNT & SW-846 Method 8515 & $16 \mathrm{mg} / \mathrm{kg}$ & $0.7 \mathrm{mg} / \mathrm{kg}$ & & \\
\hline \multirow[t]{2}{*}{3} & 2,4-DNT & SW-846 & $0.13 \mathrm{mg} / \mathrm{L}$ & $0.05 \mathrm{mg} / \mathrm{L}$ & $\pm 15 \%$ & $60-120$ \\
\hline & Nitro-benzene & Method $1311 / 82 / 0$ & $2.0 \mathrm{mg} / \mathrm{L}$ & $0.05 \mathrm{mg} / \mathrm{L}$ & & \\
\hline \multirow[t]{4}{*}{$4 \mathrm{a}$} & 1,3-DNB & SW-846 Method 8330 & $6.1 \mathrm{mg} / \mathrm{kg}$ & $0.25 \mathrm{mg} / \mathrm{kg}$ & $\pm 15 \%$ & $60-120$ \\
\hline & $\mathrm{RDX}$ & & $4.4 \mathrm{mg} / \mathrm{kg}$ & $1.0 \mathrm{mg} / \mathrm{kg}$ & & \\
\hline & TNT & & $16 \mathrm{mg} / \mathrm{kg}$ & $0.25 \mathrm{mg} / \mathrm{kg}$ & & \\
\hline & PETN & & TBD & $0.25 \mathrm{mg} / \mathrm{kg}$ & & \\
\hline \multirow[t]{4}{*}{$4 \mathrm{~b}$} & 1,3-DNB & SW-846 Method 8330 & $6.1 \mathrm{mg} / \mathrm{kg}$ & $0.25 \mathrm{mg} / \mathrm{kg}$ & $\pm 15 \%$ & $60-120$ \\
\hline & RDX & & $4.4 \mathrm{mg} / \mathrm{kg}$ & $1.0 \mathrm{mg} / \mathrm{kg}$ & & \\
\hline & TNT & & $16 \mathrm{mg} / \mathrm{kg}$ & $0.25 \mathrm{mg} / \mathrm{kg}$ & & \\
\hline & PETN & & TBD & $0.25 \mathrm{mg} / \mathrm{kg}$ & & \\
\hline \multicolumn{7}{|c|}{ Note: For more detail regarding SW-846, see Test Methods for Evaluating Solid Waste, Physical/Chemical Methods (EPA 2002a). } \\
\hline \multicolumn{7}{|c|}{$\begin{array}{l}\text { 1,3-DNB }=1,3 \text {-dinitrobenzene. } \\
\text { 2,4-DNT }=2,4 \text {-dinitrotoluene. } \\
\text { DS = decision statement. } \\
\text { EPA = Environmental Protection Agency. } \\
\text { PETN = pentaerythritol tetranitrate. } \\
\text { PQL = practical quantitation limit. } \\
\text { RDX = Royal Demolition Explosive. } \\
\text { TBD = to be determined. } \\
\text { TNT = trinitrotoluene. }\end{array}$} \\
\hline
\end{tabular}




\subsection{Study Boundaries}

The primary objective of DQO Step 4 is to identify the population of interest, define the spatial and temporal boundaries that apply to each DS, and identify any practical constraints (hindrances or obstacles) that must be taken into consideration in the sampling design. Implementing this step ensures that the sampling design will result in the collection of data that accurately reflect the true condition of the site under investigation.

\subsubsection{Population of Interest}

Before defining the spatial and temporal boundaries of the site under investigation, it is necessary to clearly define the populations of interest that apply for each DS. The populations of interest are as follows:

- DSs 1a and 1b-Soils potentially contaminated as a result of disposal by detonation operations

- DS 2 - Contaminated and potentially contaminated soil during excavation

- DS 3-Contaminated excavated soil

- DSs 4a and 4b-Remaining soil.

\subsubsection{Geographic Boundaries}

The geographic boundaries for DSs $1 \mathrm{a}$ and $1 \mathrm{~b}$ include soils that are potentially contaminated as a result of disposal activities conducted during the TNT/RDX and UXO remedial actions. The DS 1a is associated specifically with the 200-ft-diameter crater located within the MDA, while DS $1 \mathrm{~b}$ is associated with any soils impacted through disposal by in-place detonation activities at any other location within the INL. For DS 2, the geographic boundaries will be determined by visual inspection. The boundaries are expected to be less than $30 \mathrm{ft}$ in diameter and will include the "kick-out" area as determined by visual inspection of the area for shrapnel. Additionally, the boundaries are expected to be approximately $7.6 \mathrm{~cm}$ (3 in.) deep. For DS 3, the geographic boundary will be the excavated soil stockpiled prior to disposal while awaiting analysis. The geographic boundary for DSs $4 \mathrm{a}$ and $4 \mathrm{~b}$ will be the footprint of the excavations.

\subsubsection{Temporal Boundaries}

The temporal boundary refers to both the timeframe in which each DS applies and in which the data should be collected. The sample collection timeframe for DSs 1a and $1 \mathrm{~b}$ will be following the completion of all TNT/RDX and UXO disposal activities associated with OU 10-04 Phases II and IV but prior to any remediation of soils impacted by those activities. For DS 2, the sample collection timeframe is limited to the duration of the soil excavation. For DS 3, the sample collection timeframe will be following excavation prior to soil treatment (if required) and disposal. For DSs $4 a$ and $4 b$, sampling will take place after excavations are complete and field measurements demonstrate that contaminant levels are below the remedial action goals.

\subsubsection{Practical Constraints}

Practical constraints that could affect the data collection effort include physical barriers and potential background interference during field and laboratory measurements. 


\subsection{Decision Rule}

The purpose of DQO Step 5 is initially to define the statistical parameter of interest (i.e., mean or $95 \%$ UCL) that will be used for comparison against the action level. Table 3-3 summarizes the decision rules for the DSs provided in Section 3.2. These decision rules summarize the attributes the decision-maker needs to know about the sample population and how this knowledge will guide the selection of a course of action to solve the problem.

Table 3-3. Decision rules for the Operable Unit 10-04 Phase IV areas.

\begin{tabular}{|c|c|c|}
\hline DS & DR & Decision Rule \\
\hline $1 \mathrm{a}$ & $1 \mathrm{a}$ & $\begin{array}{l}\text { If the } 95 \% \text { UCL for any COC concentration exceeds the remediation goals stated in the } \\
\text { ROD (DOE-ID 2002), then the impacted soil will be removed else no remediation will be } \\
\text { required. }\end{array}$ \\
\hline $1 b$ & $1 b$ & $\begin{array}{l}\text { If the maximum concentration for any COC concentration exceeds the remediation goals } \\
\text { stated in the ROD (DOE-ID 2002), then the impacted soil will be removed else no } \\
\text { remediation will be required. }\end{array}$ \\
\hline 2 & 2 & $\begin{array}{l}\text { If any COC concentration exceeds the remediation goals stated in the ROD } \\
\text { (DOE-ID 2002), then the contaminated soil will be removed else the confirmation } \\
\text { sampling will be carried out. }\end{array}$ \\
\hline 3 & 3 & $\begin{array}{l}\text { If the TCLP concentrations exceed the regulatory level for the toxicity characteristic, } \\
\text { then the excavated soil will be stabilized prior to disposal else the excavated soil can be } \\
\text { disposed of directly. }\end{array}$ \\
\hline $4 a$ & $4 a$ & $\begin{array}{l}\text { If the concentration representing the } 95 \% \text { UCL on the true population mean for each } \\
\text { COC does not exceed the respective remedial action objective as stated in the ROD } \\
\text { (DOE-ID 2002), then the site will be designated as remediated and closeout can proceed } \\
\text { else the remediation goals have not been achieved and additional excavation is required. }\end{array}$ \\
\hline $4 b$ & $4 b$ & $\begin{array}{l}\text { If the maximum concentration for each COC does not exceed the respective remedial } \\
\text { action objective as stated in the ROD (DOE-ID 2002), then the site will be designated as } \\
\text { remediated and closeout can proceed else the remediation goals have not been achieved } \\
\text { and additional excavation is required. }\end{array}$ \\
\hline \multicolumn{3}{|c|}{$\begin{array}{l}\text { COC = contaminant of concern. } \\
\text { DOE-ID = Department of Energy Idaho Operations Office. } \\
\text { DR = decision rule. } \\
\text { DS = decision statement. } \\
\text { ROD = Record of Decision. } \\
\text { TCLP = toxicity characteristic leaching procedure. } \\
\text { UCL = upper confidence limit. }\end{array}$} \\
\hline
\end{tabular}

\subsection{Decision Error Limits}

Since analytical data can only estimate the true condition of the site under investigation, decisions that are made based on measurement data could potentially be in error (i.e., decision error). The primary objective of DQO Step 6 is to determine which DSs, if any, require a statistically based sample design with tolerable limits on the probability of making a decision error (i.e., deciding that a site is clean when residual contamination in excess of the remedial action goal remains). 
Taking into consideration the timeframe in which each of the DSs apply, the qualitative consequences of an inadequate sampling design, and the accessibility of the site if resampling is required, the soil affected by DS 4 a has been retained for a statistical sampling design.

\subsubsection{Decision Rule 1a}

For Decision Rule 1a, the two types of decision error that could occur are as follows:

- Determining that a clean site was contaminated thus requiring remediation

- Determining that a contaminated site was clean.

The decision error that has the more severe consequence is the latter, since the error could result in human health and/or ecological impacts. Given the two possible errors, null hypotheses were developed for each $\mathrm{COC}$ stating the opposite of what the investigation hopes to demonstrate. The null hypotheses are stated as follows:

- The true mean concentration of 1,3-dinitrobenzene exceeds the remedial action goal of $6.1 \mathrm{mg} / \mathrm{kg}$.

- The true mean concentration of RDX exceeds the remediation goal of $4.4 \mathrm{mg} / \mathrm{kg}$.

- $\quad$ The true mean concentration of TNT exceeds the remediation goal of $16 \mathrm{mg} / \mathrm{kg}$.

\subsubsection{Decision Rule 1b}

For Decision Rule 1b, the two types of decision error that could occur are as follows:

- Determining that a clean site was contaminated, thus requiring remediation

- Determining that a contaminated site was clean.

The decision error that has the more severe consequence is the latter, since the error could result in human health and/or ecological impacts. Given the two possible errors, null hypotheses were developed for each COC stating the opposite of what the investigation hopes to demonstrate. The null hypotheses are stated as follows:

- $\quad$ The maximum concentration of 1,3-dinitrobenzene exceeds the remedial action goal of $6.1 \mathrm{mg} / \mathrm{kg}$.

- $\quad$ The maximum concentration of RDX exceeds the remediation goal of $4.4 \mathrm{mg} / \mathrm{kg}$.

- $\quad$ The maximum concentration of TNT exceeds the remediation goal of $16 \mathrm{mg} / \mathrm{kg}$.

\subsubsection{Decision Rules 2, 4a, and 4b}

For Decision Rules 2, 4a, and 4b, the two types of decision error that could occur are as follows:

- $\quad$ Treating (managing and disposing of) clean site media as if it were contaminated

- $\quad$ Treating (managing and disposing of) contaminated site media as if it were clean.

Again, the decision error with the more sever consequence is the latter because of the potential impact on human health and/or the environment. For Decision Rules 2 and 4a, the null hypotheses are the same as those for Decision Rule 1a. For Decision Rule 4b, the null hypotheses are the same as those for Decision Rule $1 b$. 


\subsubsection{Decision Rule 3}

For Decision Rule 3, the types of decision error that could occur are as follows:

- $\quad$ Treating (managing and disposing of) non-characteristic excavated contaminated site media as if it were characteristic

- $\quad$ Treating (managing and disposing of) characteristic excavated contaminated site media as if it were not characteristic.

The decision error that has the more severe consequence is the latter, since the error could result in the direct disposal of soil that should be stabilized prior to disposal. Given the two possible errors, a null hypothesis was developed for the COCs stating the opposite of what the investigation hopes to demonstrate. The null hypotheses are stated as follows:

- The true TCLP concentration for 2,4-dinitrotoluene in soil excavated from a site exceeds the toxicity characteristic level of $0.13 \mathrm{mg} / \mathrm{L}$, as defined in 40 CFR 261.24 .

- $\quad$ The true TCLP concentration for nitrobenzene in soil excavated from a site exceeds the toxicity characteristic level of $2.0 \mathrm{mg} / \mathrm{L}$, as defined in 40 CFR 261.24.

\subsection{Design Optimization}

The objective of DQO Step 7 is to present alternative data collection designs that meet the minimum data quality requirements, as specified in DQO Steps 1-6. A selection process is then used to identify the most resource-effective data collection design that satisfies all of the data quality requirements.

The soil covered under DSs 1a, 1b, 2, 3, and $4 \mathrm{~b}$ will be sampled following a nonstatistical approach. The remaining soil addressed in DS 4 a will be sampled in accordance with a statistical design. The following subsections present the selected field-screening and sampling methods for resolving each DS along with a summary of the proposed implementation design.

\subsubsection{Soil Contamination Characterization}

To satisfy DS 1a, soil within the 200-ft-diameter crater in the MDA will be sampled following the completion of all disposal by detonation activities to determine whether contamination exists that poses an unacceptable risk to human health or the environment. The area impacted by disposal activities will be divided into 200 equal-sized grids. Samples will be collected from every tenth grid and a total of 20 samples will be collected. If the grid size exceeds $15 \mathrm{ft}$, additional grids will be added and samples will be collected every $10+$ grids for a total of 20 samples. Samples will be collected from soils potentially impacted by the disposal activities and a 95\% UCL calculated for each analyte to determine whether a COC exists that poses an unacceptable risk to human health or the environment. A total of 20 samples will be collected from which the 95\% UCL will be calculated. If the 95\% UCL for any analyte exceeds the remediation goal prescribed in the ROD (DOE-ID 2002), remediation of the impacted soil will be required.

To satisfy DS 1b, sampling of sites potentially impacted by in-place disposal by detonation activities will be performed following a multi-increment sampling scheme. Any impacted areas are expected to be less than $30 \mathrm{ft}$ in diameter. These areas will be divided into 25 equal-sized grids based upon visual determination of the impacted area and will include any "kick-out" area. Three incremental 
samples will be collected from each impacted area. The first increment will be collected from a random location in the northeast quadrant of each grid, the second increment from a random location in the northwest quadrant for each grid, and the third increment from a random location in the southeast quadrant of each grid. The increments collected from each quadrant will be of equal size, with the increments corresponding to the northeast, northwest, and southeast quadrants being combined to form three composite samples. Each composite sample will be mixed and then sieved to remove rocks or vegetation; an aliquot will then be obtained for analysis. The maximum concentration from the three composite samples will be used to evaluate the risk to human health and the environment at each impacted site. If the maximum concentration for any analyte exceeds the remediation goal prescribed in the ROD (DOE-ID 2002), remediation of the impacted site will be required.

\subsubsection{Soil Removal Survey}

To satisfy DS 2, field screening will be used to refine excavation boundaries, identify hot spots, and make decisions in the field as to where excavation is required and whether additional excavation is warranted. Final status of a site will be based on confirmation sample data. For all areas, further excavation will be performed in hot spots identified on the basis of results from field-screening samples until all contamination above the remedial action goals is removed, as demonstrated by the field-screening measurements, or until the basalt interface is exposed or a depth of $3.0 \mathrm{~m}(10 \mathrm{ft})$ is reached, whichever is less.

The initial removal of soil will involve excavating the top surface soil from those areas identified as being contaminated based upon the initial soil contamination assessment (see Section 3.7.1). Screening samples will be collected from the newly exposed soil as it is collected in the excavation areas to identify potential hot spots. All field-screening samples will be analyzed for TNT and RDX, as appropriate, using field test kits. The decision as to which test kit to use (TNT or RDX) will depend on which analyte is determined to pose an unacceptable risk to human health or the environment.

\subsubsection{Sampling for Characteristic Determination}

Sampling for characteristic determination to satisfy DS 3 will depend on the analytical results obtained during the initial soil contamination assessment. If it can be demonstrated based upon the analytical data and applying the 20X Rule of Dilution that the soil is not characteristic for either 2,4-dinitrotoluene or nitrobenzene for a given site, then no sampling of stockpiled soil originating from that site for TCLP analyses will be required. The soil will be managed in accordance with the waste management plan provided in Appendix B of the Phase IV RD/RA Work Plan (DOE-ID 2006c). If it cannot be demonstrated that the soil is not characteristic, then a single incremental sample consisting of six increments collected from different depths and locations will be collected from the soil stockpiled from a site to determine whether it exceeds the toxicity characteristic concentrations for 2,4-dinitrotoluene or nitrobenzene. 


\subsubsection{Statistical Sampling Design for Soil}

After field-screening samples indicate that COC concentrations are below the remediation goals, the statistically based sampling design will be implemented to satisfy DS 4a. The number of samples is determined using the formula in Equation (3-1), as based on Guidance on Choosing a Sampling Design for Environmental Data Collection for Use in Developing a Quality Assurance Project Plan (EPA 2002b).

$n_{d}=\sigma^{2}\left\{\frac{z_{1-\beta}+z_{1-\alpha}}{C_{s}-\mu_{1}}\right\}^{2}+\frac{1}{2}\left(z_{1-\alpha}\right)^{2}$

where

$$
\begin{aligned}
& n_{d}=\text { number of samples } \\
& \sigma^{2}=\text { sample variance } \\
& z_{1-\beta}=\quad \text { critical value for a false negative } \\
& z_{1-\alpha}=\quad \text { critical value for a false positive } \\
& C_{s}=\text { remedial action goal } \\
& \mu_{1}=\quad \begin{array}{l}
\text { mean concentration (lower bound of the gray region) where the site should be } \\
\text { declared clean. }
\end{array}
\end{aligned}
$$

As provided in the guidance, the standard deviation used in the sample size calculation is estimated as one-sixth of the measurement range, which is conservatively taken to be from zero to two times the cleanup level. Therefore, the standard deviation is equal to one-third the cleanup level of $\mathrm{C}_{\mathrm{S}} / 3$. It is reasonable to assume that the analytical methods are capable of measuring within $15 \%$ of the actual concentration; therefore, the mean concentration $\left(\mu_{1}\right)$ will be taken to be $85 \%$ of the cleanup level or $0.85 \mathrm{C}_{\mathrm{S}}$. Substituting these into the above equation yields Equation (3-2):

$n_{d}=\left(\frac{C_{S}}{3}\right)^{2}\left\{\frac{z_{1-\beta}+z_{1-\alpha}}{C_{s}-0.85 C_{S}}\right\}^{2}+\frac{1}{2}\left(z_{1-\alpha}\right)^{2}$,

which reduces further to that shown in Equation (3-3):

$n_{d}=\left(\frac{1}{3}\right)^{2}\left\{\frac{z_{1-\beta}+z_{1-\alpha}}{0.15}\right\}^{2}+\frac{1}{2}\left(z_{1-\alpha}\right)^{2}$.

The parameters of the selected statistical design for soil that provide the most resource-effective data collection design are summarized as follows:

- $\quad$ Simple random design.

- The statistical test of interest is a comparison of the 95\% UCL to the remedial action goal.

- $\quad$ Based upon previous remedial actions conducted at the INL, the false-positive ( $\alpha$ ) error rate is $5 \%$ $\left(\mathrm{Z}_{1-\alpha}=1.645\right)$. 
- $\quad$ Based upon previous remedial actions conducted at the INL, the false-negative $(\beta)$ error rate is $20 \%\left(Z_{1-\beta}=0.842\right)$.

- The lower bound of the gray region is $80 \%$ of the corresponding remedial action goal.

- $\quad$ The upper bound of the gray region is the remedial action goal for all soil and COCs.

Therefore, the number of confirmation samples is calculated as shown in Equation (3-4):

$n_{d}=\left(\frac{1}{3}\right)^{2}\left\{\frac{0.842+1.645}{0.15}\right\}^{2}+\frac{1}{2}(1.645)^{2}=31.9 \cong 32$

For the MDA, the 32 confirmation sample locations will be randomly selected from the field-screening sample locations identified during the excavation activities. To determine the validity of the data obtained using the field test kits, $20 \%$ of the samples will be sent off-Site for laboratory analysis following the SW-846 Method 8330 (EPA 2002a). A regression analysis will be performed to determine whether the laboratory-generated data correlate with the data obtained from the field test kits. If the correlation squared $\left(\mathrm{R}^{2}\right)$ is greater than 0.70 , the data sets will be considered comparable, and the data from the field test kits combined with that from the laboratory will be used to confirm whether the remediation goals have been met for the individual sites. If $\mathrm{R}^{2}$ is less than 0.70 , the data sets will not be considered comparable, and the sites for which $100 \%$ of the samples were not submitted for laboratory analysis will be resampled with all samples sent off-Site for laboratory analysis.

After collection and analysis, the 95\% UCL will be compared to the final remediation goal for COCs in the soil. If the data are normally distributed, the null hypothesis will be tested by comparing the $95 \%$ UCL to the final remediation goal. Normality of the data will be tested graphically and through use of the Shapiro-Wilk statistic (e.g., a statistical calculation). If data are not normally distributed, then an appropriate transform (i.e., log normal) will be implemented. If transformation of the data is necessary, then the transformed $95 \%$ UCL will be compared to the transformed cleanup standard. The transformed $95 \%$ UCL shall not be transformed back for comparison to the untransformed cleanup standard. The 95\% UCL is given as shown in Equation (3-5):

$U C L=\bar{x}+\frac{(t \cdot s)}{\sqrt{n}}$

where

$$
\begin{array}{lll}
\bar{x} & = & \text { sample average or xbar } \\
t & = & \text { test statistic obtained from statistical tables } \\
s & = & \text { standard deviation of the sample population } \\
n & = & \text { number of samples. }
\end{array}
$$

It is important to note that the $t$-value is based on the degrees of freedom or the number of measurements/samples above the instrument detection limit, minus one. Any measurements that are "less-than-detectable" will not be considered in the UCL calculation. However, when calculating the sample population mean, less-than-detectable values will be taken as the calculated instrument detection limit. 


\subsection{Quality Assurance Objectives for Measurement}

The quality assurance (QA) objectives for measurement will meet or surpass the minimum requirements for data quality indicators established in the QAPjP (DOE-ID 2006a). This reference provides minimum requirements for the following measurement quality indicators: precision, accuracy, representativeness, detection limits, completeness, and comparability. Precision, accuracy, and completeness will be calculated in accordance with the QAPjP (DOE-ID 2006a).

\subsubsection{Precision}

Precision is a measure of the reproducibility of measurements under a given set of conditions. In the field, precision is affected by sample collection procedures and by the natural heterogeneity encountered in the environment. Overall precision (field and laboratory) can be evaluated by the use of duplicate samples collected in the field. Typically, greater precision is required for analytes with very low action levels that are close to background concentrations.

Laboratory precision will be based upon the use of laboratory-generated duplicate samples or matrix spike/matrix spike duplicate samples. Evaluation of laboratory precision will be performed during the method data validation process.

Field precision will be based upon the analysis of collected field duplicate or split samples. For samples collected for laboratory analyses, a field duplicate will be collected at a minimum frequency of 1 in 10 environmental samples.

Precision of field-screening samples for TNT and RDX will be based on the collection of duplicate samples and duplicate measurements. Duplicate samples and measurements will be collected at a frequency of 1 in 10 field-screening samples and 1 in 10 field measurements.

\subsubsection{Accuracy}

Accuracy is a measure of bias in a measurement system. Laboratory accuracy is demonstrated using laboratory control samples, blind quality control (QC) samples, and matrix spikes. Evaluation of laboratory accuracy will be performed during the method data validation process. Sample handling, field contamination, and the sample matrix in the field affect overall accuracy. False-positive or high-biased sample results will be assessed by evaluating results from field blanks, trip blanks, and equipment rinsates.

Field accuracy will only be determined for samples collected for laboratory analysis. The accuracy of field instrumentation will be ensured through the use of appropriate calibration procedures and standards. In addition, field sample results will be assessed by evaluating results from blank soil samples wherein the soil used for the analysis will be collected from an area immediately adjacent to the contaminated area. The blank soil samples will be analyzed at the beginning of each sampling day and at a total frequency of 1 in 20 field-screening samples with a minimum of $10 \%$ of the blank soil samples also being submitted for laboratory analysis.

\subsubsection{Representativeness}

Representativeness is a qualitative parameter that expresses the degree to which the sampling and analysis data accurately and precisely represent the characteristic of a population parameter being measured at a given sampling point or for a process or environmental condition. Representativeness will be evaluated by determining whether measurements are made and physical samples are collected in such 
a manner that the resulting data appropriately measure the media and phenomenon measured or studied. The comparison of all field and laboratory analytical data sets obtained throughout this remedial action will be used to ensure representativeness.

\subsubsection{Detection Limits}

Detection limits for laboratory analyses will meet or exceed the remediation goals for the COCs. Detection limits will be as specified in the Sample and Analysis Management (SAM) laboratory Master Task Agreement statements of work, task order statements of work, and as described in the QAPjP (DOE-ID 2006a).

Detection limits for field instrumentation also will meet or exceed the remedial action goals for the COCs and are noted in Table 3-2.

\subsubsection{Completeness}

Completeness is a measure of the quantity of usable data collected during the field-sampling activities. The QAPjP (DOE-ID 2006a) requires that an overall completeness goal of $90 \%$ must be achieved for noncritical samples. If critical parameters or samples are identified, a 100\% completeness goal is specified. Critical data points are those sample locations or parameters for which valid data must be obtained in order for the sampling event to be considered complete. For this project, all field-screening data will be considered noncritical with a completeness goal of $90 \%$. The laboratory data collected for confirmation samples will be considered critical with a completeness goal of $100 \%$.

\subsubsection{Comparability}

Comparability is a qualitative characteristic that refers to the confidence with which one data set can be compared to another. At a minimum, comparable data must be obtained using unbiased sampling designs. If sampling designs are not unbiased, the reasons for selecting another design should be well documented. Data comparability will be assessed by comparing all data sets collected during this study for the following parameters:

- Data sets will contain the same variables of interest.

- Units will be expressed in common metrics.

- Similar analytical procedures and QA will be used to collect data.

- $\quad$ Time of measurements of variables will be similar.

- Measuring devices will have similar detection limits.

- Samples within data sets will be selected in a similar manner.

- $\quad$ Number of observations will be of the same order of magnitude. 


\subsection{Data Validation}

Method data validation is the process whereby analytical data are reviewed against set criteria to ensure that the results conform to the requirements of the analytical method and any other specified requirements.

All laboratory-generated analytical data will be validated to Level A in accordance with Guide (GDE) -7003, "Levels of Analytical Method Data Validation." Level A validation is the most stringent validation level requiring review of all laboratory quality assurance/quality control (QA/QC) data as well as raw data generated as a result of the analytical process.

Field-generated data will not be validated. Quality of the field-generated data will be ensured through adherence to established operating procedures and use of equipment calibration (as appropriate). 


\section{SAMPLING DESIGN SUMMARY}

The material presented in this section is intended to support the DQOs summarized in Section 3. Field-screening measurements in conjunction with confirmation samples will be collected to support the DQOs presented in Section 3.

\subsection{Quality Assurance/Quality Control Samples}

The QA samples will be included to satisfy the QA requirements for the field operations in accordance with the QAPjP (DOE-ID 2006a). The duplicate, blank, and calibration (QA/QC) samples will be analyzed as outlined in Section 3.8.

\subsection{Sampling Locations and Frequency}

Sampling is required initially to assess whether a site poses an unacceptable risk attributed to disposal by detonation activities. If it is determined that a site poses an unacceptable risk, subsequent sampling will be required to confirm that the remediation goals and, hence, the remedial action objectives have been achieved. The following sections discuss the locations and frequency with which samples will be collected from the individual sites covered under this FSP.

\subsubsection{Mass Detonation Area}

Sampling activities at the MDA will include the collection of characterization samples, field survey samples, and confirmation samples. In addition, samples will be collected from stockpiled soils to determine whether they exceed the action level for the toxicity characteristic regulatory concentration as defined in 40 CFR 261.24.

As outlined in Section 3.7.1, characterization samples will be collected from the MDA soils with the potential to have been adversely impacted by the disposal activities conducted in support of the remediation of the TNT/RDX- and UXO-contaminated sites. Disposal activities are performed in a large 200-ft-diameter crater located at the MDA; therefore, characterization sampling will be limited to the soil within the crater and the "kick-out" area immediately surrounding the crater. A sampling grid will be established over the area with a minimum of 200 sampling nodes. The number of nodes will be selected so that each node will be less than $15 \mathrm{ft}$ on each side. Samples will be collected from every tenth grid if the number of grids is 200 or at the frequency needed to collect a total of 20 samples if the number of grids is different from 200. These samples will be submitted for nitroaromatics analysis. Based upon the results of these analyses, it will be determined whether the soil poses an unacceptable risk to human health or the environment, thus requiring remediation of the site.

If remediation is required, field survey samples will be used to define the extent of excavation. As excavation activities progress, field survey samples will be collected and analyzed for TNT and RDX, using commercially available field test kits to determine when the remedial action goals have been achieved. This process of excavation followed by field survey sampling will continue until the remedial action goals have been achieved for the area.

Once the field survey samples demonstrate that the remedial action goals have been met, confirmation samples will be analyzed using field test kits with a subset of $20 \%$ sent to an approved analytical laboratory for correlation analysis. Thirty-two samples will be collected for analysis from the surface of the exposed soil. The sample locations will be determined in the field and will be based upon 
the relative size of the excavated zone within the MDA. Based on the results of the analyses, there are two options:

- If the confirmation analyses show that the results are below the remedial action goals for all of the COCs based upon calculation of the $95 \%$ UCL, then the remedial action will be considered complete.

- If the confirmation analyses show that the results are above the remedial action goals for any of the COCs based upon calculation of the 95\% UCL, additional hot spot excavation will be conducted in the suspected area(s) where the sample(s) were collected, and additional confirmation analyses will be performed. This process will be repeated until the analytical results show that the remedial action objectives have been met or until all soil is removed to basalt.

\subsubsection{Impacted Soil Areas}

If any UXO must be detonated in place rather than transported to the MDA for disposal, the potential exists that the surrounding soil may be adversely impacted by the disposal activity. Sampling of a site potentially impacted by in-place disposal by detonation activities will be performed following a multi-increment sampling scheme as outlined in Section 3.7.1. If remediation is required as determined from the characterization sampling, field survey samples will be used to define the extent of excavation. As excavation activities progress, field survey samples will be collected and analyzed for TNT and RDX using commercially available field test kits to determine when the remedial action goals have been achieved. This process of excavation followed by field survey sampling will continue until the remedial action goals have been achieved for the area.

It is anticipated that any area adversely impacted by in-place disposal by detonation activities will be limited in size. Therefore, the determination as to whether the remediation goals have been achieved will follow the same approach as that for characterization, with a grid established over the area and multi-increment sampling used to assess whether the remediation goals have been achieved. As with the MDA, two options exist for the impacted area based upon the analytical results:

- If the confirmation analyses show that the results are below the remedial action goals for all of the COCs based upon calculation of the 95\% UCL, then the remedial action will be considered complete.

- If the confirmation analyses show that the results are above the remedial action goals for any of the COCs based upon calculation of the $95 \%$ UCL, additional hot spot excavation will be conducted in the suspected area(s) where the sample(s) were collected, and additional confirmation analyses will be performed. This process will be repeated until the analytical results show that the remedial action objectives have been met or until all soil is removed to basalt. 


\section{SAMPLING DESIGNATION}

\subsection{Sample Identification Code}

A systematic character identification (ID) code will be used to uniquely identify all confirmation samples. Uniqueness is required for maintaining consistency and preventing the same ID code from being assigned to more than one sample.

The first two designators of the code, $U X$, refer to the sample originating in support of the UXO remedial action. The third and fourth designators correspond to the specific area from which the sample is being collected, as follows:

- $\quad 11-\mathrm{NODA}$

- $\quad 12-\mathrm{MDA}$

- $\quad 13$-Experimental Field Station

- $\quad 14-$ Rail Car Explosion Area

- $\quad$ 15-Land Mine Fuze Burn Area

- $\quad 16-$ Other.

The next two numbers designate the sequential sample number collected from a given area. A two-character set (i.e., 01, 02) will be used to designate field duplicate samples. The last two characters refer to a particular analysis and bottle type. Personnel shall refer to the SAP tables, which will be prepared prior to sampling, for specific bottle code designations.

For example, a soil sample collected in support of confirming the nitroaromatic concentrations at the NODA might be designated as UX110101N7 where (from left to right):

- $\quad \mathbf{U X}$ designates the sample as originating in support of the UXO remedial action.

- $\mathbf{1 1}$ corresponds to the sample being collected from the NODA.

- $\quad 01$ designates the sequential sample number.

- $\quad 01$ designates the type of sample $(01=$ original, $02=$ field duplicate $)$.

- $\quad$ N7 designates nitroaromatic analysis.

A SAP table/database will be used to record all pertinent information associated with each sample ID code.

\subsection{Sampling and Analysis Plan Table/Database}

\subsubsection{Sampling and Analysis Plan Table}

A SAP table format was developed to simplify the presentation of the sampling scheme for project personnel. The following sections describe the information recorded in the SAP table/database. The SAP table(s) will be prepared prior to conducting sampling. 


\subsubsection{Sample Description}

The sample description fields contain information relating individual sample characteristics.

5.2.2.1 Sampling Activity. The sampling activity field contains the first six characters of the assigned sample number. The sample number in its entirety will be used to link information from other sources (i.e., field data, analytical data) to the information in the SAP table for data reporting, sample tracking, and completeness reporting. The analytical laboratory also will use the sample number to track and report analytical results.

5.2.2.2 Sample Type. Data in this field will be selected from the following:

- $\quad$ REG-for a regular sample

- $\quad \mathrm{QC}$ - for a QC sample.

5.2.2.3 Media. Data in this field will be selected from the following:

- $\quad$ SOIL-for soil samples

- WATER-for QA/QC water samples.

5.2.2.4 Collection Type. Data in this field will be selected from the following:

- $\quad$ GRAB - for grab sample collection

- $\quad$ RNST — for rinsate QA/QC samples

- DUP_for field duplicate samples

- $\quad$ FBLK — for field blank QA/QC samples

- $\quad$ TBLK - for trip blank QA/QC samples.

5.2.2.5 Planned Date. This date is related to the planned sample collection start date.

\subsubsection{Sample Location Fields}

This group of fields pinpoints the exact location for the sample in three-dimensional space, starting with the general AREA, narrowing the focus to an exact location geographically, and then specifying the DEPTH in the depth field.

5.2.3.1 Area. The AREA field identifies the general sample collection area. This field should contain the standard identifier for the INL area being sampled. For this investigation, the AREA field identifier will correspond to one of the five sites being remediated. The site codes associated with the five sites are as follows:

- ORD-06-NODA

- ORD-13-MDA

- ORD-15-Experimental Field Station

- ORD-19-Rail Car Explosion Area

- $\quad$ ORD-24-Land Mine Fuze Burn Area. 
5.2.3.2 Location. The LOCATION field may contain geographical coordinates, $x-y$ coordinates, building numbers, or other location-identifying details as well as program-specific information such as borehole or well number. Data in this field will normally be subordinated to the AREA. This information is included on the labels generated by the SAM Program to aid sampling personnel.

5.2.3.3 Type of Location. The TYPE OF LOCATION field supplies descriptive information concerning the exact sample location. Information in this field may overlap that in the location field, but it is intended to add detail to the location.

5.2.3.4 Depth. The DEPTH of a sample location is the distance in feet from surface level or a range in feet from the surface.

\subsubsection{Analysis Types (AT1-AT2O)}

The AT1-AT20 fields indicate analysis types (i.e., radiological, chemical, and hydrological). Space is provided at the bottom of the form to clearly identify each type. A standard abbreviation also should be provided if possible. 


\section{SAMPLING PROCEDURES AND EQUIPMENT}

The following subsections describe the sampling procedures and equipment to be used for the planned sampling and analyses described in this FSP. Before commencement of any sampling activities, a prejob briefing will be held to review the requirements of the FSP and the project HASP (PLN-2128) and to ensure that all supporting documentation has been completed.

\subsection{Sampling Requirements}

Sampling requirements for Phase IV of the OU 10-04 remedial action sampling are outlined in the following sections. Table 6-1 provides the requirements for sample containers, preservation methods, sample volumes, and holding times for soil and QA/QC samples. The specific analyses required are provided in Section 3.

Table 6-1. Specific sample requirements for the Operable Unit 10-04 Phase IV remedial action.

\begin{tabular}{|c|c|c|c|c|c|c|}
\hline \multirow{2}{*}{$\begin{array}{l}\text { Analytical } \\
\text { Parameter }\end{array}$} & \multicolumn{2}{|c|}{ Container } & \multirow{2}{*}{$\begin{array}{l}\text { Sample } \\
\text { Matrix }\end{array}$} & \multirow[b]{2}{*}{ Preservative } & \multirow{2}{*}{$\begin{array}{l}\text { Analytical } \\
\text { Method }\end{array}$} & \multirow{2}{*}{$\begin{array}{l}\text { Holding } \\
\text { Time }\end{array}$} \\
\hline & Size & Type & & & & \\
\hline Nitroaromatics ${ }^{\mathrm{a}}$ & $4 \mathrm{oz}$ & AWM glass & Soil & Cool to $4^{\circ} \mathrm{C}$ & $\begin{array}{l}\text { SW- } 846 \\
\text { Method } 8330\end{array}$ & $\begin{array}{l}14 \text { days to } \\
\text { extraction/ } 40 \text { days } \\
\text { after extraction }\end{array}$ \\
\hline Nitroaromatics $^{\mathrm{a}}$ & $1 \mathrm{~L}$ & Amber glass & Water & $\begin{array}{l}0.008 \% \mathrm{Na}_{2} \mathrm{~S}_{2} \mathrm{O}_{3}{ }^{\mathrm{b}} \\
\text { Cool to } 4^{\circ} \mathrm{C}\end{array}$ & $\begin{array}{l}\text { SW-846 } \\
\text { Method } 8330\end{array}$ & $\begin{array}{l}7 \text { days to } \\
\text { extraction/ } 40 \text { days } \\
\text { after extraction }\end{array}$ \\
\hline TCLP SVOCs & $250 \mathrm{~mL}$ & WM glass & Soil & Cool to $4^{\circ} \mathrm{C}$ & $\begin{array}{l}\text { SW-846 } \\
1311 / 8270\end{array}$ & $\begin{array}{l}7 \text { days to } \\
\text { extraction/ } 40 \text { days } \\
\text { after extraction }\end{array}$ \\
\hline \multicolumn{7}{|c|}{$\begin{array}{l}\text { a. The sampling and analysis plan table will specify contaminants for which the sample will be analyzed. } \\
\text { b. If residual chlorine is present, add } 80 \mathrm{mg} \text { of sodium thiosulfate }\left(\mathrm{Na}_{2} \mathrm{~S}_{2} \mathrm{O}_{3}\right) \text { per liter of sample. }\end{array}$} \\
\hline $\begin{array}{l}\text { AWM = amber wide } \\
\text { SVOC = semivolatile } \\
\text { TCLP = toxicity char } \\
\text { WM = wide-mouth. }\end{array}$ & $\begin{array}{l}\text { outh. } \\
\text { rganic col } \\
\text { teristic le }\end{array}$ & ind. & & & & \\
\hline
\end{tabular}

\subsubsection{Field Measurements}

Field-screening samples will be collected in support of the remedial activities at the OU 10-04 sites to guide excavation and to support the decision that the remedial action objectives have been met for the individual sites. The following subsections describe the field-screening methods and the associated project requirements associated with the measurement systems.

6.1.1.1 Trinitrotoluene Field Test Kit. The TNT EnSys Soil Test System will be used to provide rapid, quantitative field-screening results. The effective concentration range of the test is between 1 and $30 \mathrm{ppm}$ with a standard deviation of $8 \%$ and a minimum detection limit of $0.7 \mathrm{ppm}$. The soil test-kit system will be used with either the Hach Model \#DR/2000 or \#DR/2010 spectrophotometer. The spectrophotometer will be prepared for operation in accordance with the procedure provided by the manufacturer. Soil samples will be air-dried before analysis to minimize analytical variation.

The basic analytical approach involves weighing an aliquot of the soil sample followed by extraction with acetone. The extract is filtered to remove sediment and the filtrate is dispensed in a sample cuvette for final preparation and analysis in the spectrophotometer. A TNT control sample shall be 
analyzed each day prior to sample analysis. For sample concentrations greater than the effective concentration range of the method (i.e., $30 \mathrm{ppm}$ ), the sample extract shall be further diluted with acetone until the sample concentration falls within the effective range. Analytical results are interpreted in accordance with the manufacturer's instructions. The TNT test kit expiration date will be checked prior to use to be sure that the kit is not expired. Results obtained from expired test kits will not be used.

6.1.1.2 Royal Demolition Explosive Field Test Kit. The RDX EnSys Soil Test System will be used to provide rapid, quantitative field-screening results. The effective concentration range of the test is between 1 and $30 \mathrm{ppm}$ with a standard deviation of $10 \%$ and a minimum detection limit of $0.8 \mathrm{ppm}$. The soil test-kit system will be used with either the Hach Model \#DR/2000 or \#DR/2010 spectrophotometer. The spectrophotometer will be prepared for operation in accordance with the procedure provided by the manufacturer. Soil samples will be air-dried before analysis to minimize analytical variation.

The basic analytical approach involves weighing an aliquot of the soil sample followed by extraction with acetone. The extract is filtered to remove sediment and the filtrate is dispensed in a reaction vial for reaction with NitriVer powder and color development. The contents are expelled into the sample cuvette for analysis in the spectrophotometer. An RDX control sample shall be analyzed each day prior to sample analysis. For sample concentrations greater than the effective concentration range of the method (i.e., $30 \mathrm{ppm}$ ), the sample extract shall be further diluted with acetone until the sample concentration falls within the effective range. Analytical results are interpreted in accordance with the manufacturer's instructions. The RDX test kit expiration date will be checked prior to use to be sure that the kit is not expired. Results obtained from expired test kits will not be used.

\subsubsection{Soil Sampling}

Samples will be collected from surface soil following the completion of all TNT/RDX and UXO disposal activities to assess whether the activities adversely impacted the surrounding area. In addition, surface soil samples will be collected following excavation to guide the continued excavation of soil, if needed, and to confirm that the remediation goals have been achieved. The surface soil samples will be collected in accordance with the procedures outlined in GDE-155, "Collecting Samples Using Scoops, Spoons, and Shovels." Samples will be collected between 0 to $7.6 \mathrm{~cm}$ ( 0 to 3 in.) in depth using a decontaminated trowel, spoon, or shovel. If soil conditions are not conducive to sampling by this method, either a thief sampler or hand auger may be used. Sampling methods employed will be noted in the sampling logbook.

Samples will be collected from the excavated, stockpiled soils to determine whether the soil is characteristic. The stockpiled soil samples will be collected following the procedures outlined in GDE-152, "Collecting Samples Using a Hand Auger." A single incremental sample, consisting of six increments collected from different depths and locations, will be collected from the soil stockpiled from a site to determine whether it exceeds the toxicity characteristic concentrations for 2,4-dinitrotoluene or nitrobenzene.

Each surface or stockpile sample will be sieved, using a stainless-steel spoon, through a 2-mm (0.08-in.) mesh stainless-steel screen into a disposable aluminum pan to remove all large rocks and debris. Following sample collection, the soil in the aluminum pan will be thoroughly mixed with the stainless-steel spoon and containers will be filled for laboratory analysis. Sample material left over will be returned to the location from which it originated.

Decontamination of sampling equipment will be performed in accordance with GDE-162, "Decontaminating Sampling Equipment." Dry decontamination methods will be used to the extent practicable to minimize the generation of liquid decontamination waste. 


\subsection{Handling and Disposition of Sampling Residues and Related Waste}

Remediation waste will be generated during the sampling activities as described herein. Waste generated at all sites will be considered nonhazardous and not characteristic for RCRA constituents. Samples will be handled in accordance with MCP -3480, "Environmental Instructions for Facilities, Processes, Materials and Equipment." All waste streams generated from the sampling activity will be characterized in accordance with MCP-1390, "Waste Generator Services Waste Management," and will be handled, stored, and disposed of accordingly.

Waste will be generated as a result of the sampling activities conducted during this project. Waste expected to be generated during the sampling includes the following:

- $\quad$ Personal protective equipment (PPE)

- Unused/unaltered sample material

- $\quad$ Analytical residues

- $\quad$ Sample containers

- $\quad$ Miscellaneous waste

- $\quad$ Contaminated equipment.

As sampling continues, additional waste streams may be identified. All new waste streams projected, as well as those identified above, are required to have the waste identified and characterized. A hazardous waste determination will be completed for all waste generated during the OU 10-04 Phase IV remedial action.

The waste associated with the sampling activities will be managed in a manner that complies with the established applicable or relevant and appropriate requirements (ARARs), protects human health and the environment, and achieves minimization of remediation waste to the extent possible. The ARARs applicable to the storage of waste are defined in accordance with the ROD (DOE-ID 2002). The basic provisions of the ARARs provide for appropriate waste containerization and compliant storage of the remediation waste for an interim storage period. Protection of human health and the environment is achieved through implementation of the ARARs and through implementation of the waste management approach described in the Waste Management Plan provided in Appendix B of the Phase IV RD/RA Work Plan (DOE-ID 2006c).

\subsubsection{Laboratory Samples}

As part of the contract for the subcontracted laboratory, all laboratory and sample waste is managed in accordance with the SAM master task agreements. The laboratory will dispose of any unused sample material. The laboratories are responsible for any waste generated as a result of analyzing the samples.

In the event that unused sample material must be returned from the laboratory, only the unused and unaltered samples in the original sample containers will be accepted from the laboratory and only with approval of the CERCLA remedial project manager. These samples will be returned to the waste stream from which they originated. If the laboratory must return altered sample material (e.g., analytical residue), the laboratory will specifically define the types of chemical additives used in the analytical process and assist in making a hazardous waste determination. This information will be provided to the project field 
team leader and environmental compliance coordinator. Management of this waste also will require separation from the other unaltered samples being returned.

\subsection{Project-Specific Waste Streams}

Several distinct waste stream types anticipated to be generated during this project have been identified. Some of these waste types will be clean, but many could be contaminated. Subsequent to generation, any or all of the waste may be reclassified; therefore, the intended waste management strategies for each are outlined in Sections 6.3.1 through 6.3.6. These sections describe the expected sampling waste that will require compliant storage and/or disposal, including the intended management strategy from the time of generation until final disposition. Field and laboratory personnel will be responsible for segregating the waste. The anticipated quantities have been approximated; however, they are considered a rough order-of-magnitude because, in some cases, the type of contamination present cannot be determined before sampling and analysis. Estimated waste volumes are based on historical sampling activities conducted in support of other CERCLA actions conducted at the INL.

\subsubsection{Personal Protective Equipment}

The PPE in the form of coveralls, leather and rubber gloves, shoe covers or boots, and other anticontamination clothing may be generated during the sampling activities. The anticipated quantity of PPE to be generated and requiring disposal as a result of the sampling activities for each of the sites is $0.76 \mathrm{~m}^{3}\left(1 \mathrm{yd}^{3}\right)$, classified as conditional industrial.

\subsubsection{Unused/Unaltered Sample Material}

Unused/unaltered sample material will be generated from the sampling activities in the form of soil not required for sampling and analysis. Generally, the analytical laboratory will be responsible for disposal of the unused/unaltered sample material. In those cases where samples must be returned from the laboratory, this excess material will be managed in accordance with MCP-3002, "Managing Disturbed Soils." Whenever possible, all unused/unaltered sample material received by the INL for disposal will be returned to the point of origin. Conditions that may preclude the return of soil to the original sampling location include, but are not limited to, the following:

- $\quad$ Soil layer might have been excavated

- Backfill material might have been placed over the sample location

- Analytical results show that the sample material contains contaminants in excess of the remedial action goals.

If conditions preclude the return of unused/unaltered sample material to the point of origin, then the sample material will require disposal at an approved facility such as the Idaho CERCLA Disposal Facility (ICDF).

\subsubsection{Analytical Residues}

Analytical residues will be generated from the sample analytical activities conducted by subcontracted and/or on-Site laboratories. Although the laboratories are required to dispose of analytical residues under terms of the subcontract, the potential does exist for return of analytical residues. The anticipated quantity of analytical residues to be generated and requiring disposal as a result of the field-sampling activities is $0.76 \mathrm{~m}^{3}\left(1 \mathrm{yd}^{3}\right)$, classified as conditional industrial. 


\subsubsection{Sample Containers}

Sample containers will become a waste stream following analyses. The sample containers will be wiped clean. The sample containers will be disposed of as conditional industrial waste at the CFA landfill. The anticipated quantity of sample containers to be generated and requiring disposal as a result of the field-sampling activities is $0.76 \mathrm{~m}^{3}\left(1 \mathrm{yd}^{3}\right)$, classified as conditional industrial.

\subsubsection{Miscellaneous Waste}

Miscellaneous waste such as trash, labels, rags, wipes, and other miscellaneous debris might be generated during the field-sampling activities. Clean miscellaneous waste will be removed to the CFA landfill. The anticipated quantity of miscellaneous waste to be generated and requiring disposal as a result of the field-sampling activities is $1.53 \mathrm{~m}^{3}\left(2 \mathrm{yd}^{3}\right)$, classified as conditional industrial.

\subsubsection{Contaminated Sampling Equipment}

Contaminated equipment will become a waste stream in the event that it cannot be decontaminated or reused for another project and disposal is required. Contaminated sampling equipment (e.g., hand augers, spoons, pans, and screens) will be expected to be decontaminated. 
6-6 


\section{DOCUMENTATION MANAGEMENT AND SAMPLE CONTROL}

Section 7.1 summarizes document management and sample control. Documentation includes field logbooks used to record field data and sampling procedures. Section 7.2 outlines the sample handling and discusses chain of custody for shipment to the analytical laboratory. The analytical results from this sampling effort will be documented in the remedial action report.

\subsection{Documentation}

The field team leader will be responsible for controlling and maintaining all field documents and records and for ensuring that all required documents will be submitted to the ICP Administrative Records and Document Control Center. All entries will be made in permanent ink. All errors will be corrected by drawing a single line through the error and entering the correct information. All corrections will be initialed and dated.

\subsubsection{Sample Container Labels}

Waterproof, gummed labels generated from the SAP database will display information such as the sample ID number, the name of the project, sample location, and analysis type. In the field, labels will be completed and placed on the containers before collecting the sample. Information concerning sample date, time, preservative used, field measurements of hazards, and the sampler's initials will be filled out during field sampling.

\subsubsection{Field Guidance Forms}

Field guidance forms provided for each sample location will be generated from the SAP database to ensure unique sample numbers. Used to facilitate sample container documentation and organization of field activities, these forms contain information regarding the following:

- $\quad$ Media

- $\quad$ Sample ID numbers

- $\quad$ Sample location

- $\quad$ Aliquot ID

- $\quad$ Analysis type

- $\quad$ Container size and type

- $\quad$ Sample preservation.

\subsubsection{Field Logbooks}

In accordance with the Administrative Records and Document Control format, field logbooks will be used to record information necessary to interpret the analytical data. All field logbooks will be controlled and managed according to MCP-1194, "Logbook Practices for ICP CERCLA and Removal Action Projects." 
7.1.3.1 Sample/Shipping Logbooks. The field team will use sample logbooks. Each sample logbook will contain information such as the following:

- $\quad$ Physical measurements (if applicable)

- $\quad$ All QC samples

- $\quad$ Sample date, time, and location

- $\quad$ Shipping information (e.g., collection dates, shipping dates, cooler ID number, destination, COC number, and name of shipper).

7.1.3.2 Field Team Leader's Daily Logbook. An operational logbook maintained by the field team leader will contain a daily summary of the following:

- $\quad$ All the project field activities

- $\quad$ Problems encountered

- Visitor $\log$

- List of site contacts.

This logbook will be signed and dated at the end of each day's sampling activities.

7.1.3.3 Field Instrument Calibration/Standardization Logbook. A logbook containing records of calibration data will be maintained for each piece of equipment requiring periodic calibration or standardization. This logbook will contain log sheets to record the date, time, method of calibration, and instrument ID number.

\subsection{Sample Handling}

All samples will be handled in accordance with MCP-9228, "Managing Nonhazardous Samples" or MCP-1394, "Managing Hazardous Samples," as applicable. Qualified (SAM-approved) analytical and testing laboratories will be used to analyze the samples. Analytical samples for analyses will be collected in precleaned bottles and packaged in accordance with Section 2.3.2.1, "Sample Containers," in the QAPjP (DOE-ID 2006a).

\subsubsection{Sample Preservation}

Preservation of water samples will be performed immediately upon sample collection. If required for preservation, acid may be added to the bottles prior to sampling. For samples requiring controlled temperatures of $4^{\circ} \mathrm{C}\left(39^{\circ} \mathrm{F}\right)$ for preservation, the temperature will be checked periodically before shipment to certify adequate preservation. Ice chests (coolers) containing frozen, reusable ice will be used to chill the samples, if required, in the field after sample collection.

\subsubsection{Chain-of-Custody Procedures}

The chain-of-custody procedures will be followed in accordance with the requirements of Program Requirements Document (PRD) -5030, "Environmental Requirements for Facilities, Processes, Materials and Equipment"; MCP-3480, "Environmental Instructions for Facilities, Processes, Materials and Equipment"; MCP-1192, "Chain-of-Custody and Sample Labeling for ICP CERCLA and Removal Action Sampling Activities"; and the QAPjP (DOE-ID 2006a). Sample bottles will be stored in a secured area that is accessible only to the field team members. For field-screening samples that remain under 
control of the field team and are not transferred to another entity for analysis, formal written chain of custody will not be required.

\subsubsection{Transportation of Samples}

Samples will be shipped in accordance with the regulations issued by the Department of Transportation (DOT) (49 CFR 171-178) and EPA sample handling, packaging, and shipping methods (40 CFR 261.4[d]). All samples will be packaged in accordance with the requirements set forth in MCP-3480 and PRD-5030.

7.2.3.1 Custody Seals. Custody seals will be placed on all shipping containers in such a way as to ensure that sample integrity is not compromised by tampering or unauthorized opening. Clear plastic tape will be placed over the seals to ensure that the seals are not damaged during shipment.

7.2.3.2 On-Site and Off-Site Shipping. An on-Site shipment is any transfer of material within the perimeter of the INL. Site-specific requirements for transporting samples within Site boundaries and those required by the shipping/receiving department will be followed. Shipment within the INL boundaries will conform to DOT requirements, as stated in 49 CFR, "Transportation." Off-Site sample shipment will be coordinated with Packaging and Transportation personnel, as necessary, and will conform to all applicable DOT requirements. 


\section{REFERENCES}

40 CFR 261.4, 2006, "Exclusions," Code of Federal Regulations, Office of the Federal Register, October 2006.

40 CFR 261.24, 2006, "Toxicity Characteristic," Code of Federal Regulations, Office of the Federal Register, October 2006.

40 CFR 300, 2006, "National Oil and Hazardous Substances Pollution Contingency Plan," Code of Federal Regulations, Office of the Federal Register, October 2006.

49 CFR, 2006, "Transportation," Code of Federal Regulations, Office of the Federal Register, November 2006.

49 CFR 171, 2006, "General Information, Regulations, and Definitions," Code of Federal Regulations, Office of the Federal Register, October 2006.

49 CFR 172, 2006, "Hazardous Materials Table, Special Provisions, Hazardous Materials Communications, Emergency Response Information, and Training Requirements," Code of Federal Regulations, Office of the Federal Register, October 2006.

49 CFR 173, 2006, "Shippers - General Requirements for Shipments and Packagings," Code of Federal Regulations, Office of the Federal Register, October 2006.

49 CFR 174, 2006, "Carriage by Rail," Code of Federal Regulations, Office of the Federal Register, January 2006.

49 CFR 175, 2006, "Carriage by Aircraft," Code of Federal Regulations, Office of the Federal Register, October 2006.

49 CFR 176, 2006, "Carriage by Vessel," Code of Federal Regulations, Office of the Federal Register, January 2006.

49 CFR 177, 2006, "Carriage by Public Highway," Code of Federal Regulations, Office of the Federal Register, October 2006.

49 CFR 178, 2006, "Specifications for Packagings," Code of Federal Regulations, Office of the Federal Register, October 2006.

42 USC § 6901 et seq., 1976, "Resource Conservation and Recovery Act (Solid Waste Disposal Act)," United States Code, October 21, 1976.

DOE-ID, 1991, Federal Facility Agreement and Consent Order for the Idaho National Engineering Laboratory, Administrative Docket No. 1088-06-29-120, U.S. Department of Energy Idaho Operations Office; U.S. Environmental Protection Agency, Region 10; Idaho Department of Health and Welfare, December 4, 1991.

DOE-ID, 1998, Preliminary Scoping Track 2 Summary Report for Operable Unit 10-03 Ordnance, DOE/ID-10566, Rev. 0, Volumes 1 and 2, U.S. Department of Energy Idaho Operations Office, January 1998. 
DOE-ID, 2001, Comprehensive Remedial Investigation/Feasibility Study for Waste Area Groups 6 and 10 Operable Unit 10-04, DOE/ID-10807, Rev. 0, Volumes I and II, U.S. Department of Energy Idaho Operations Office, August 2001.

DOE-ID, 2002, Record of Decision Experimental Breeder Reactor-I/Boiling Water Reactor Experiment Area and Miscellaneous Sites, Operable Units 6-05 and 10-04, DOE/ID-10980, Rev. 0, U.S. Department of Energy Idaho Operations Office; U.S. Environmental Protection Agency, Region 10; Idaho Department of Environmental Quality, November 2002.

DOE-ID, 2004, Operations and Maintenance Plan for Operable Units 6-05 and 10-04, Phase II, DOE/NE-ID-11130, Rev. 0, U.S. Department of Energy Idaho Operations Office, August 2004.

DOE-ID, 2005, Remedial Action Report for Operable Units 6-05 and 10-04, Phase I, DOE/NE-ID-11186, Rev. 0, U.S. Department of Energy Idaho Operations Office, January 2005.

DOE-ID, 2006a, Quality Assurance Project Plan for Waste Area Groups 1, 2, 3, 4, 5, 6, 7, 10, and Removal Actions, DOE/ID-10587, Rev. 9, U.S. Department of Energy Idaho Operations Office, July 2006.

DOE-ID, 2006b, INL Sitewide Institutional Controls Plan, DOE/ID-11042, Rev. 3, U.S. Department of Energy Idaho Operations Office, July 2006.

DOE-ID, 2006c, Remedial Design/Remedial Action Work Plan for Operable Units 6-05 and 10-04, Phase IV, DOE/ID-11261, Rev. 0, U.S. Department of Energy Idaho Operations Office, November 2006.

EPA, 1994, Guidance for the Data Quality Objectives Process, EPA QA/G-4, EPA/600/R-96/055, Office of Research and Development, U.S. Environmental Protection Agency, September 1994.

EPA, 2002a, Test Methods for Evaluating Solid Waste, Physical/Chemical Methods, SW-846, Rev. 5, U.S. Environmental Protection Agency, Office of Solid Waste, August 2002.

EPA, 2002b, Guidance on Choosing a Sampling Design for Environmental Data Collection for Use in Developing a Quality Assurance Project Plan, EPA/240/R-02/005, U.S. Environmental Protection Agency, December 2002.

GDE-152, 2006, “Collecting Samples Using a Hand Auger,” Rev. 1, Environmental Services Program ES Characterization Sampling Handbook, Idaho National Laboratory, Idaho Cleanup Project, September 2006.

GDE-155, 2006, “Collecting Samples Using Scoops, Spoons, and Shovels,” Rev. 1, Environmental Services Program ES Characterization Sampling Handbook, Idaho National Laboratory, Idaho Cleanup Project, September 2006.

GDE-162, 2004, “Decontaminating Sampling Equipment,” Rev. 1, Environmental Services Project Characterization Sampling Handbook, Idaho National Engineering and Environmental Laboratory, April 2004.

GDE-7003, 2006, "Levels of Analytical Method Data Validation," Rev. 4, Sample and Analysis Administrative Manual, Idaho National Laboratory, Idaho Cleanup Project, October 2006. 
INEEL, 2004, Long-Term Ecological Monitoring Plan for the Idaho National Engineering and

Environmental Laboratory, INEEL/EXT-02-01191, Rev. 1, Idaho National Engineering and Environmental Laboratory, Idaho Completion Project, January 2004.

INL, 2005, Idaho National Laboratory Comprehensive Land Use and Environmental Stewardship Report, INL/EXT-05-00726, Idaho National Laboratory, September 2005.

MCP-1192, 2006, "Chain-of-Custody and Sample Labeling for ICP CERCLA and Removal Action Sampling Activities,” Rev. 3, Idaho National Laboratory, Idaho Cleanup Project, September 2006.

MCP-1194, 2006, "Logbook Practices for ICP CERCLA and Removal Action Projects," Rev. 3, Idaho National Laboratory, Idaho Cleanup Project, September 2006.

MCP-1390, 2006, "Waste Generator Services Waste Management," Rev. 1, Manual 17-Waste Management, Idaho National Laboratory, Idaho Cleanup Project, June 2006.

MCP-1394, 2006, “Managing Hazardous Samples,” Rev. 1, Environmental Services Administration Handbook, Idaho National Laboratory, Idaho Cleanup Project, September 2006.

MCP-1432, 2006, "Roles and Responsibilities of the Miscellaneous Sites Personnel," Rev. 3, Idaho National Laboratory, Idaho Cleanup Project, September 2006.

MCP-3002, 2006, "Managing Disturbed Soils," Rev. 6, Manual 8-Environmental Protection and Compliance, Idaho National Laboratory, Idaho Cleanup Project, June 2006.

MCP-3480, 2006, "Environmental Instructions for Facilities, Processes, Materials and Equipment," Rev. 12, Manual 8-Environmental Protection and Compliance, Idaho National Laboratory, Idaho Cleanup Project, June 2006.

MCP-9228, 2005, “Managing Nonhazardous Samples,” Rev. 6, Environmental Services Administration Handbook, Idaho National Laboratory, Idaho Cleanup Project, September 2005.

MCP-9439, 2006, "Environmental Sampling Activities at the INL," Rev. 4, Manual 8-Environmental Protection and Compliance, Idaho National Laboratory, Idaho Cleanup Project, June 2006.

PLN-2087, 2006, "Project Execution Plan for the Miscellaneous Sites Cleanup," Rev. 4, Idaho National Laboratory, Idaho Cleanup Project, October 2006.

PLN-2128, 2006, "Miscellaneous Sites Cleanup Project Health and Safety Plan,” Rev. 2, Idaho National Laboratory, Idaho Cleanup Project, October 2006.

PRD-5030, 2006, "Environmental Requirements for Facilities, Processes, Materials and Equipment," Rev. 6, Manual 8-Environmental Protection and Compliance, Idaho National Laboratory, Idaho Cleanup Project, June 2006. 